\title{
Design of a Functionalized Metal-Organic Framework System for Enhanced Targeted Delivery to Mitochondria
}

\author{
Salame Haddad, Isabel Abánades Lázaro, Marcus Fantham, Ajay Mishra, Joaquin Silvestre-Albero, \\ Johannes W. M. Osterrieth, Gabriele S. Kaminski Schierle,* Clemens F. Kaminski,* Ross S. Forgan,* \\ and David Fairen-Jimenez*
}

Cite This: J. Am. Chem. Soc. 2020, 142, 6661-6674

Read Online

ACCESS | 네 Metrics \& More | 国 Article Recommendations | sl Supporting Information

ABSTRACT: Mitochondria play a key role in oncogenesis and constitute one of the most important targets for cancer treatments. Although the most effective way to deliver drugs to mitochondria is by covalently linking them to a lipophilic cation, the in vivo delivery of free drugs still constitutes a critical bottleneck. Herein, we report the design of a mitochondria-targeted metal-organic framework (MOF) that greatly increases the efficacy of a model cancer drug, reducing the required dose to less than $1 \%$ compared to the free drug and ca. $10 \%$ compared to the nontargeted MOF. The performance of the system is evaluated using a holistic approach ranging from microscopy to transcriptomics. Super-resolution microscopy of MCF-7 cells treated with the targeted MOF system reveals important mitochondrial

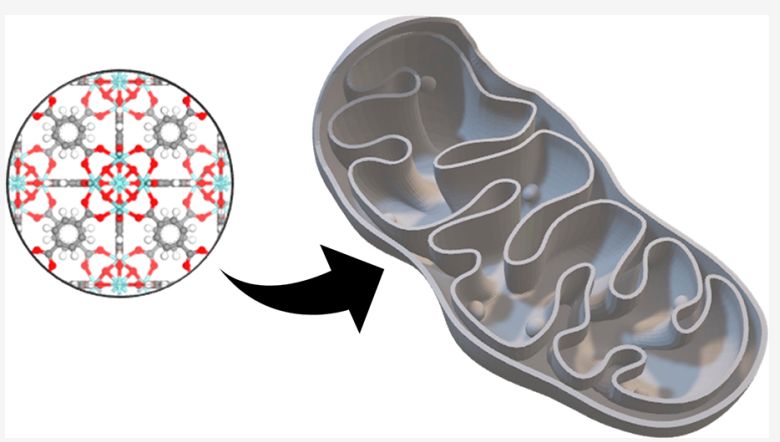
morphology changes that are clearly associated with cell death as soon as $30 \mathrm{~min}$ after incubation. Whole transcriptome analysis of cells indicates widespread changes in gene expression when treated with the MOF system, specifically in biological processes that have a profound effect on cell physiology and that are related to cell death. We show how targeting MOFs toward mitochondria represents a valuable strategy for the development of new drug delivery systems.

\section{INTRODUCTION}

While the survival rate for most cancers has doubled over the past 40 years, some cancers, such as those of the pancreas, brain, lung, and esophagus, still have very poor prognoses. To improve cancer therapies, an enormous effort has been directed at obtaining a better fundamental understanding of the mechanisms of cancer growth and the differences in the metabolism between healthy and cancer cells. In particular, it is known that mitochondria play a key role in oncogenesis and thus constitute promising targets for novel cancer treatments. ${ }^{1}$ Mitochondria are the energy powerhouse of cells; noncancerous, healthy mammalian cells normally produce their energy by oxidative phosphorylation using the electron transport chain in the mitochondrial matrix. Cancerous cells, however, utilize glycolysis, even in the presence of oxygen. ${ }^{2}$ This is due in part to a reprogramming of mitochondrial function in cancer cells that increases pyruvate dehydrogenase kinase (PDK) activity, which limits the uptake of pyruvate at a level necessary for oxidative phosphorylation. ${ }^{3}$

In addition to cellular metabolism, and related to novel cancer treatments, mitochondria are involved heavily in the regulation of cell death. Evasion of cell death is a trademark feature of cancer ${ }^{4}$ and is a determining factor in the growth of tumor cell populations. ${ }^{5}$ Apoptosis, part of the cell death machinery, mostly involves proteases known as caspases
(CASP), which are only activated when cell death is triggered. Permeabilization of the mitochondrial outer membrane triggers the caspase cascade, making treatment strategies that cause mitochondrial permeabilization attractive. ${ }^{6-8}$ This is especially true given that the mitochondria of cancer cells are structurally and functionally different than those of their healthy cell counterparts and are more susceptible to perturbations, ${ }^{9}$ making mitochondrial targeting a means to also selectively target cancer cells. As such, targeting cancer cells specifically and reverting their mitochondrial metabolism to oxidative phosphorylation as well as activating apoptosis is an attractive strategy in cancer treatment.

The use of nanotechnology to design drug delivery systems (DDSs) has made significant strides in cancer therapies by improving the pharmacokinetics and biodistribution of therapeutic agents. ${ }^{10}$ Advances in nanoformulations allow the delivery of drugs in their pristine form, the solubilization of hydrophobic drugs, an increase in their half-life, and a

Received: January 9, 2020

Published: March 17, 2020 
Table 1. Characterization of the UiO-66-Based Drug Delivery System Particles ${ }^{a}$

\begin{tabular}{|c|c|c|c|c|c|c|}
\hline MOF & particle size ${ }^{b}(\mathrm{~nm})$ & effective diameter ${ }^{c}(\mathrm{~nm})$ & PdI & $Z$-potential $(\mathrm{mV})$ & DCA loading (wt \%) & TPP loading (wt \%) \\
\hline $\mathrm{DCA}_{10}-\mathrm{UiO}-66$ & $81 \pm 27$ & $257 \pm 1$ & 0.17 & 35.4 & 15.5 & 0 \\
\hline $\mathrm{DCA}_{5}-\mathrm{UiO}-66$ & $115 \pm 48$ & $308 \pm 1$ & 0.17 & 35.3 & 10.0 & 0 \\
\hline $\mathrm{DCA}_{2.5}-\mathrm{UiO}-66$ & $139 \pm 51$ & $348 \pm 4$ & 0.21 & 35.5 & 6.1 & 0 \\
\hline $\mathrm{DCA}_{5}-\mathrm{TPP}_{5}-\mathrm{UiO}-66$ & $131 \pm 51$ & $660 \pm 26$ & 0.51 & 42.2 & 13.0 & 2.3 \\
\hline TPP@(DCA $10-\mathrm{UiO}-66)$ & $81 \pm 27$ & $302 \pm 2$ & 0.28 & 9.3 & 2.2 & 14.6 \\
\hline TPP@(DCA $-\mathrm{UiO}-66)$ & $115 \pm 48$ & $394 \pm 6$ & 0.35 & 12.9 & 1.2 & 7.0 \\
\hline TPP@(DCA 2.5 -UiO-66) & $139 \pm 51$ & $471 \pm 10$ & 0.35 & 10.0 & 1.5 & 15.0 \\
\hline
\end{tabular}

${ }^{a}$ Particle size, polydispersity (PdI), Z-potential, and DCA and TPP loadings (by ICP-OES) of the different samples. ${ }^{b}$ Measured by SEM-errors represent the standard deviation of 100 particles. ${ }^{c}$ Measured by DLS in water.

reduction of their side effects and immunogenicity. Among DDSs, functional nanoparticles are attractive candidates for selective targeting due to the possibility of modifying their external surfaces. Metal-organic frameworks (MOFs) in particular have arisen in the last years as favorable candidates for nanomedicine applications, owing to their unique properties. $^{11-17}$ Indeed, among the more than 90,000 structures reported in the Cambridge Structural Database, many MOFs show high porosity and very large surface areas (as high as $8000 \mathrm{~m}^{2} / \mathrm{g}$ ), along with a highly tunable surface chemistry and pore size. ${ }^{18}$ In addition, the synthesis of MOFs allows fine control over particle size and shape, which is difficult to achieve with other systems. To date, a number of therapeutics have been encapsulated in MOFs, including anticancer, antibacterial, and antiviral drugs, as well as nucleic acids and biological gases. ${ }^{19-24}$ We have previously demonstrated that it is possible to extend the release of cargo from the MOF framework by collapsing its porosity around the payload, either mechanically ${ }^{25,26}$ or thermally. ${ }^{14}$ We have also demonstrated that it is possible to easily functionalize the external surface of MOFs to enhance their colloidal stability and immunogenecity and improve their cellular uptake by directing them to clathrinor caveolae-mediated endocytic pathways. ${ }^{16,27,28}$ We have also shown that it is possible to design MOFs to obtain clinically relevant nanoparticulate DDSs that are able to bypass lysosomal degradation. ${ }^{28}$ In addition, a number of studies have shown the attachment of small molecules and peptides to specifically target cancerous cells. ${ }^{29-32}$ Very recently, some studies have demonstrated a high level of mitochondrial targeting that resulted in improved efficacy of microwaveassisted thermal ${ }^{33}$ and radio/radiodynamic therapy. ${ }^{34}$

Here, we report the design and testing of a $\mathrm{Zr}-\mathrm{MOF}, \mathrm{UiO}-66$ ( $\mathrm{UiO}=$ Universitetet $\mathrm{i}$ Oslo), loaded with the cancer drug dichloroacetate (DCA) and conjugated with triphenylphosphonium (TPP), which localizes to mitochondria. On the one hand, DCA is a small molecule that inhibits PDK, reversing cancer cell metabolism from aerobic glycolysis to oxidative phosphorylation. ${ }^{35}$ This shift is accompanied by a downregulation of the abnormally high mitochondrial membrane potential, reduced proliferation, and increased apoptosis of cancerous cells. ${ }^{35,36}$ However, the hydrophilicity of DCA means that it does not efficiently cross cell membranes and so must be administered as part of a DDS to show any significant efficiency. On the other hand, TPP is a lipophilic cation that exhibits a single positive charge resonance stabilized over three phenyl groups and a large hydrophobic area. ${ }^{37}$ TPP is known to accumulate readily in mitochondria of living cells, driven by the mitochondrial membrane potential. ${ }^{38-40}$ We have combined the design of the DDS and in vitro experiments with super-resolution microscopy in order to detect mitochon- drial morphological changes associated with autophagy and cell death in unprecedented detail. We also reveal the genome-wide changes in transcription, related to cell death and metabolism, using a whole-transcriptome analysis of cells treated with our system. Altogether, using this holistic approach, our obtained data clearly indicate a profound enhancement of the therapeutic efficacy of DCA by the NPs presented here.

\section{RESULTS AND DISCUSSION}

Zirconium-based MOFs such as $\mathrm{UiO}-66$ are a promising option for drug delivery, given the low toxicity of its components ${ }^{17}$ and large porosity $\left(S_{\mathrm{BET}}=1200 \mathrm{~m}^{2} \mathrm{~g}^{-1}, V_{\mathrm{p}}=\right.$ $\left.0.5 \mathrm{~cm}^{3} \mathrm{~g}^{-1}\right)$. The pristine structure of this MOF consists of $\mathrm{Zr}$ oxo clusters linked together by benzene dicarboxylate (BDC) units to give the overall composition $\left[\mathrm{Zr}_{6} \mathrm{O}_{4}(\mathrm{OH})_{4}(\mathrm{BDC})_{6}\right]_{n}$. The stability of $\mathrm{UiO}-66$ in water and in vivo environments is also critical. ${ }^{41,42}$ We have shown in the past that UiO-66 generally shows good stability in water but it is quickly degraded in the presence of phosphate salts (e.g., PBS), although in growth media the stability is enhanced due to the formation of a protein corona around the particles. ${ }^{17}$ Moreover, the specific use of DCA as a defect-inducing modulator is also known to enhance aqueous colloidal stability. ${ }^{43}$ To find a UiO-66 system with optimal mitochondrial targeting properties, we first synthesized three materials using DCA as a modulator, which is trapped in significant quantities at defect sites and the particle outer surfaces. ${ }^{30} \mathrm{We}$ named the materials $\mathrm{DCA}_{x}-\mathrm{UiO}-66$, where $x$ is the molar equivalent of DCA relative to the linker in the initial reaction conditions. Second, we attached 4-carboxybutyltriphenylphosphonium (TPP) postsynthetically to their external surface; we named these materials TPP@( $\left.\mathrm{DCA}_{x}-\mathrm{UiO}-66\right)$. Third, we synthesized a separate UiO-66 sample with both DCA and TPP as modulators, hence incorporating them during the synthesis; we called this sample $\mathrm{DCA}_{5}-\mathrm{TPP}_{5}-\mathrm{UiO}-66$. Figure $\mathrm{S} 1$ shows the powder X-ray diffraction (PXRD) patterns for the samples compared with the pattern predicted from the single crystal structure, confirming the crystallinity of UiO-66 irrespective of whether TPP is incorporated during the synthesis procedure or afterward. Table 1 shows the particle sizes of the materials determined from SEM (Figure S2), the colloidal analysis obtained from dynamic light scattering (DLS) in water as well as the DCA and TPP loadings, calculated by inductively coupled plasma optical emission spectroscopy (ICP-OES); Figures S3 and S4 show the ${ }^{1} \mathrm{H}$ NMR spectra and TGA profiles. Particle sizes as determined from SEM range from 81 to $139 \mathrm{~nm}$ for $\mathrm{DCA}_{10}-\mathrm{UiO}-66$ and $\mathrm{DCA}_{2.5}-\mathrm{UiO}-66$, respectively, and are within the correct size range for cellular uptake. DCA loadings range from 1.2 to 15.5 wt $\%$, whereas TPP loadings range between 2.3 and 15.0 wt \%. 
Unsurprisingly, TPP loadings were much higher when added postsynthetically but the DCA loading was reduced, probably due to additional steps in the overall synthesis. Figures S5 and S6 show the FTIR spectra, and Figure S7 shows the $\mathrm{N}_{2}$ adsorption isotherms at $77 \mathrm{~K}$.

In addition to particle size, colloidal stability is critical for intracellular delivery applications. $\mathrm{DCA}_{10}-\mathrm{UiO}-66, \mathrm{DCA}_{5}-\mathrm{UiO}-$ 66 , and $\mathrm{DCA}_{2.5}-\mathrm{UiO}-66$ have hydrodynamic diameters of 257 , 308 , and $348 \mathrm{~nm}$ in water, respectively, with polydispersity (PdI) values ranging from 0.17 to 0.21 (Table 1 ). Also, the addition of TPP postsynthetically (i.e., TPP@(DCA $-\mathrm{UiO}-66)$ samples) shows a slight increase $(18-23 \%)$ in hydrodynamic diameter compared to pristine $\mathrm{DCA}_{x}-\mathrm{UiO}-66$ samples, with PdI values ranging from 0.28 to 0.35 . The only exception is TPP@(DCA 2.5 -UiO-66), with an increment in hydrodynamic diameter of $35 \%$. Even though the hydrodynamic diameters for all of the particles increase compared to SEM, they remain within the size range that cells can take up by endocytosis, while still displaying good colloidal stability in pure water. $\mathrm{DCA}_{x}-\mathrm{UiO}-66$ samples show similar $z$-potential values, at around $35.4 \mathrm{mV}$, whereas the postsynthetic addition of TPP decreases them to $7.9-15.1 \mathrm{mV}$ (Table 1). This, however, does not affect the colloidal stability of the particles, as shown by PdI values below 0.36 . The only exception here is $\mathrm{DCA}_{5}$ $\mathrm{TPP}_{5}$-UiO-66, which, despite the high $z$-potential of $42.2 \mathrm{mV}$, has lower colloidal stability, with a PdI of 0.51 . It is notable that postsynthetic loading of TPP gives much higher incorporation $(7-15 \% w / w)$ than direct inclusion of TPP in MOF synthesis but also leads to a significant loss of DCA cargo, suggesting detachment under these conditions. In our postsynthetic modification, reduction of the zeta potential can only be related to changes in the external surface chemistry, for example, related to the loss of DCA and linker molecules. Zeta potentials in MOFs have proven to be very difficult to interpret, as there is a large number of factors that affect them due to their porous and coordination nature. In particular, the bulk chemistry greatly affects the external surface chemistry and is dependent on factors such as the number of defects and the constituent molecules forming the porosity. In the past, we have observed large variations of the zeta potential in UiO-66 samples to similar values to the ones we observed here, corroborating our observations. ${ }^{40}$

To investigate the cytotoxicity of the different materials, we first ran an MTS assay for MCF-7 cells, analyzing it against both the DDS and DCA concentrations to determine whether the observed toxicity is due to DCA alone or other properties inherent to the DDS (Figure 1a). When plotted against DDS concentration, $\mathrm{DCA}_{10}-\mathrm{UiO}-66$ and $\mathrm{DCA}_{5}-\mathrm{UiO}-66$ have a comparable effect on MCF-7 cells, decreasing viability to ca. $67 \%$ at $1 \mathrm{mg} / \mathrm{mL}$, whereas $\mathrm{DCA}_{2.5}-\mathrm{UiO}-66$ and $\mathrm{DCA}_{5}-\mathrm{TPP}_{5}-$ UiO-66 have a more pronounced effect with 48 and $36 \%$ viability, respectively. When plotted against DCA concentration, however, the different samples have different effects on cell viability, indicating that toxicity is not solely dependent on DCA concentration. Factors such as particle size and surface chemistry have been shown to play a role in determining the cellular uptake efficiency and endocytosis pathways that nanoparticles use to enter cells. ${ }^{28,44}$ Since the different samples have different physicochemical properties and because of the low loading of TPP $(2.3 \% w / w)$ by direct incorporation into synthesis, it is difficult to isolate the effect of TPP as a targeting functionality. Direct incorporation may also result in localization of TPP throughout the porosity of the MOF, and not solely at the particle external surface, further reducing any targeting effect.

To control for the effect of particle size and isolate the effect of TPP as a targeting agent, we then investigated the cytotoxicity of the postsynthetically modified samples, again, as a function of DDS and DCA concentration (Figure 1b). Looking at the cell viability reduction, with values ranging from 35 to $23 \%$ at $1 \mathrm{mg} / \mathrm{mL}$ (Figure $1 \mathrm{~b}$, top), the addition of TPP to the external surface dramatically increases the cytotoxicity of the materials by mitochondrial targeting. When plotted against equivalent DCA concentration, the effect is even more important, where the cell viability was dramatically reduced even at low concentrations of DCA (Figure $1 \mathrm{~b}$, bottom). Importantly, in TPP samples, we required a ca. 10-fold lower concentration of DCA, compared to nontargeted $\mathrm{DCA}_{x}-\mathrm{UiO}$ 66 , to achieve the same reduction in viability. To validate the hypothesis of the synergistic effect of TPP, DCA, and UiO-66, Figure S7 shows the cytotoxicity of the DCA drug alone, TPP alone, DCA+TPP, naked UiO-66, and UiO-66 transporting TPP (i.e., TPP@MOF). The results show that the individual molecules and the TPP@MOF were not toxic up to concentrations of $1 \mathrm{mg} / \mathrm{mL}$, confirming previous examples in the literature. ${ }^{45-47}$ All of this proves that the increase in toxicity is due to the drug delivery vehicle targeting to mitochondria.

We investigated further the mitochondrial targeting abilities of TPP@(DCA $-\mathrm{UiO}-66)$ and $\mathrm{DCA}_{5}-\mathrm{TPP}_{5}-\mathrm{UiO}-66$; we included $\mathrm{DCA}_{5}-\mathrm{UiO}-66$ as a nontargeted control. In order to verify the structural information and the homogeneity of the loaded MOFs, we ran transmission electron microscopy (TEM) and X-ray photoelectron spectra (XPS) measurements on these three samples. Figure S8 shows the TEM images, confirming the sizes of the particles obtained from SEM; Table S1 shows the external surface composition (atomic \%) for the three samples, $\mathrm{DCA}_{5}-\mathrm{UiO}-66, \mathrm{TPP} @\left(\mathrm{DCA}_{5}-\mathrm{UiO}-66\right)$, and $\mathrm{DCA}_{5}-\mathrm{TPP}_{5}-\mathrm{UiO}-66$, and Figures $\mathrm{S} 9$ and $\mathrm{S} 10$ show a detailed analysis of the $\mathrm{C} 1 \mathrm{~s}, \mathrm{O} 1 \mathrm{~s}, \mathrm{Zr} 3 \mathrm{~d}, \mathrm{P} 2 \mathrm{p}$, and $\mathrm{Cl} 2 \mathrm{p}$ regions. All samples contain $\mathrm{C}, \mathrm{O}$, and $\mathrm{Zr}$ coming preferentially from the MOF network, while $\mathrm{P}$ is detected only for samples containing TPP and $\mathrm{Cl}$ is detected from DCA. These results confirm the successful incorporation of TPP and DCA in the UiO-66 formulation. A closer look at these values shows that the $\mathrm{Cl}$ percentage is slightly larger for sample $\mathrm{DCA}_{5}-\mathrm{UiO}-66$ compared to $\mathrm{DCA}_{5}-\mathrm{TPP}_{5}-\mathrm{UiO}-66$ (2.5 at \% vs 2.1 at \%), in agreement with ICP-OES analysis. $\mathrm{DCA}_{5}-\mathrm{TPP}_{5}-\mathrm{UiO}-66$ also shows a certain amount of $\mathrm{P}(0.1$ at $\%)$, thus confirming the successful incorporation of TPP in the formulation. Interestingly, the postsynthesis modification of $\mathrm{DCA}_{5}-\mathrm{UiO}-66$ with TPP gives rise to important changes. The percentage of $\mathrm{P}$ increases to 0.3 at \%, while the amount of $\mathrm{Cl}$ goes down to 0.5 at $\%$. This observation suggests that TPP is mainly located at the MOF external surface, while DCA either remains in the inner porosity (not detectable by XPS) or it is detached from the structure after TPP incorporation. Another important finding after TPP incorporation is the significant decrease in the amount of $\mathrm{C}$ and the increase in the amount of $\mathrm{Zr}$ and $\mathrm{O}$. These observations could be associated with changes in the surface structure during the incorporation of the TPP targeting unit. These changes can be more clearly appreciated in the $\mathrm{O}$ 1 s region (Figure S9).

Figure 1c shows the time-dependent MTS viability in order to determine the kinetics of toxicity of the three MOFs on MCF-7 cells as a function of DDS and DCA concentration. For 
a.
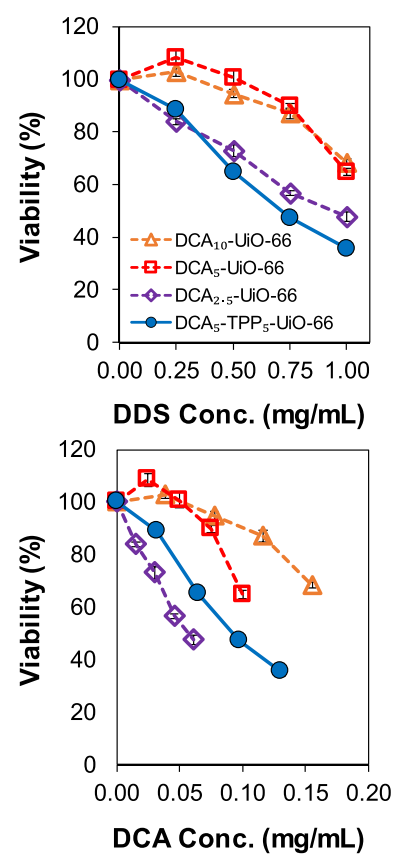

b.

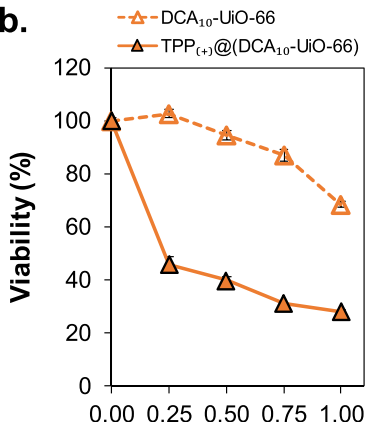

DDS Conc. (mg/mL)

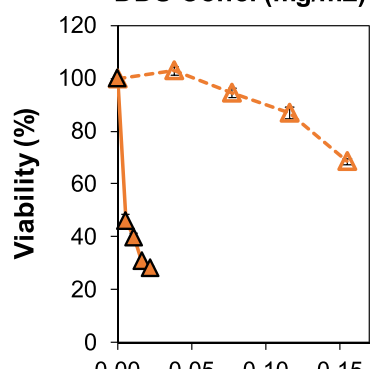

DCA Conc. (mg/mL)
- - - DCA - -UiO-66

$\rightarrow-\mathrm{TPP}_{(+)} @\left(\mathrm{DCA}_{5}-\mathrm{UiO}-66\right)$

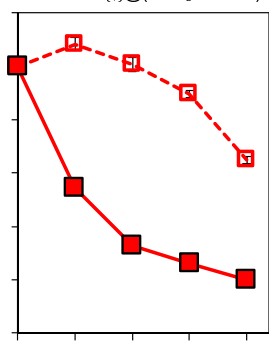

$\begin{array}{lllll}0.00 & 0.25 & 0.50 & 0.75 & 1.00\end{array}$

DDS Conc. (mg/mL)

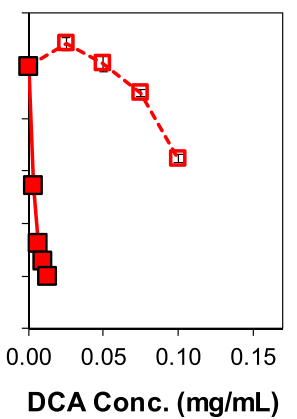

$-\diamond-\mathrm{DCA}_{2 \cdot 5}-\mathrm{UiO}-66$

$\leadsto-\mathrm{TPP}_{(+)} @\left(\mathrm{DCA}_{2 \cdot 5}-\mathrm{UiO}-66\right)$

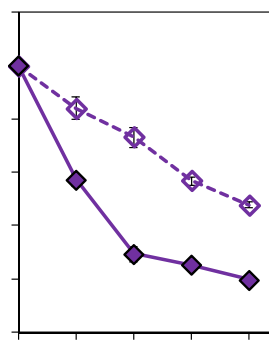

$\begin{array}{lllll}0.00 & 0.25 & 0.50 & 0.75 & 1.00\end{array}$

DDS Conc. (mg/mL)

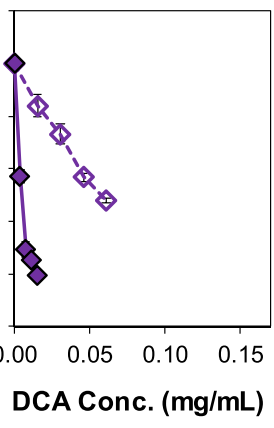

c. $4 \mathrm{~h}$ $8 \mathrm{~h}$ $24 \mathrm{~h}$ $48 \mathrm{~h}$ $72 \mathrm{~h}$
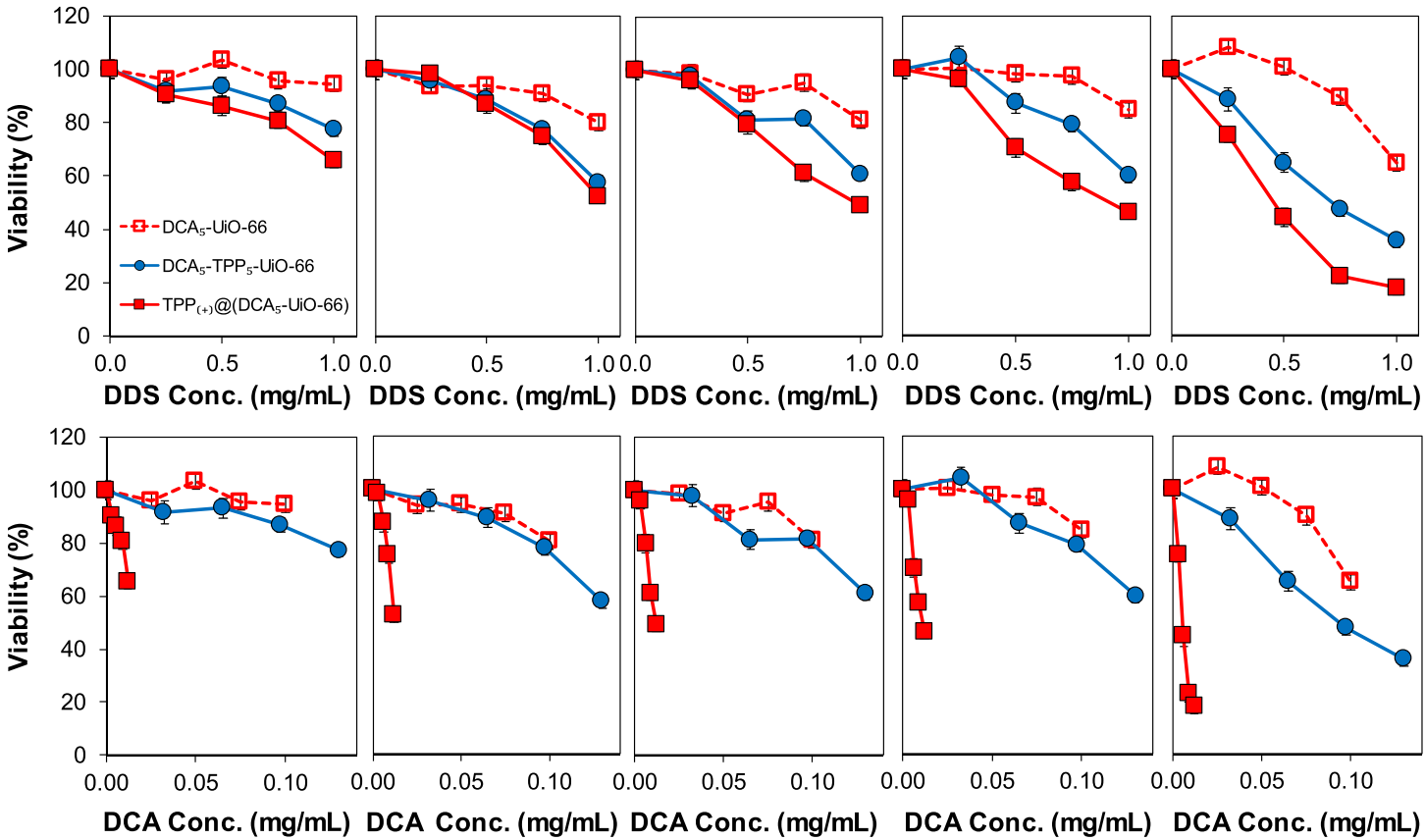

Figure 1. MTS viability assay of MCF-7 cells after incubation with different systems. (a) Cell viability as a function of DDS (top) and equivalent DCA concentration (bottom) after incubation for $72 \mathrm{~h}$ with different DCA-loaded DDSs. (b) Cell viability as a function of DDS (top) and equivalent DCA concentration (bottom) after incubation for $72 \mathrm{~h}$ with $\mathrm{DCA}_{x}-\mathrm{UiO}-66$ and TPP@(DCA - -UiO-66). (c) Cell viability as a function of DDS (top) and equivalent DCA concentration (bottom) after incubation for 4-72 h with DCA $-\mathrm{UiO}_{5}-66, \mathrm{TPP} @\left(\mathrm{DCA}_{5}-\mathrm{UiO}_{-66}\right)$, and DCA 5 $\mathrm{TPP}_{5}$-UiO-66. Error bars-sometimes smaller than the symbol sizes-represent the standard error of the mean of five replicate measurements.

the two materials containing TPP, we observe toxicity as early as $4 \mathrm{~h}$. At a DDS concentration of $1 \mathrm{mg} / \mathrm{mL}$, viability decreases to 78 and $66 \%$ for $\mathrm{DCA}_{5}-\mathrm{TPP}_{5}-\mathrm{UiO}-66$ and TPP@(DCA $\mathrm{UiO}-66)$, respectively, decreasing further as time progresses but stabilizing between 8 and 48 h down to values of ca. 60$50 \%$. At $72 \mathrm{~h}$, viability reduces further down to 36 and $12 \%$ for both MOFs at $1 \mathrm{mg} / \mathrm{mL}$ concentration. $\mathrm{DCA}_{5}-\mathrm{UiO}-66$, on the other hand, remains nontoxic up to $48 \mathrm{~h}$, showing only slight toxicity after $72 \mathrm{~h}$ at the highest concentration of $1 \mathrm{mg} / \mathrm{mL}$ (viability ca. 63\%). When plotted as a function of DCA concentration, it is clear that TPP@( $\left.\mathrm{DCA}_{5}-\mathrm{UiO}-66\right)$, which has the lowest levels of DCA loading and TPP present only on the external surface, is the most toxic material, causing a sharp decrease in cell viability after as soon as $4 \mathrm{~h}$ of incubation. Interestingly, when comparing the toxicity of $\mathrm{DCA}_{5}-\mathrm{TPP}_{5^{-}}$ UiO-66 and DCA $_{5}-\mathrm{UiO}-66$ based on DCA concentration, they show similar performance for times below $72 \mathrm{~h}$. At $72 \mathrm{~h}$, $\mathrm{DCA}_{5}-\mathrm{TPP}_{5}-\mathrm{UiO}-66$ seems to be more active than $\mathrm{DCA}_{5}-\mathrm{UiO}-$ 
a.

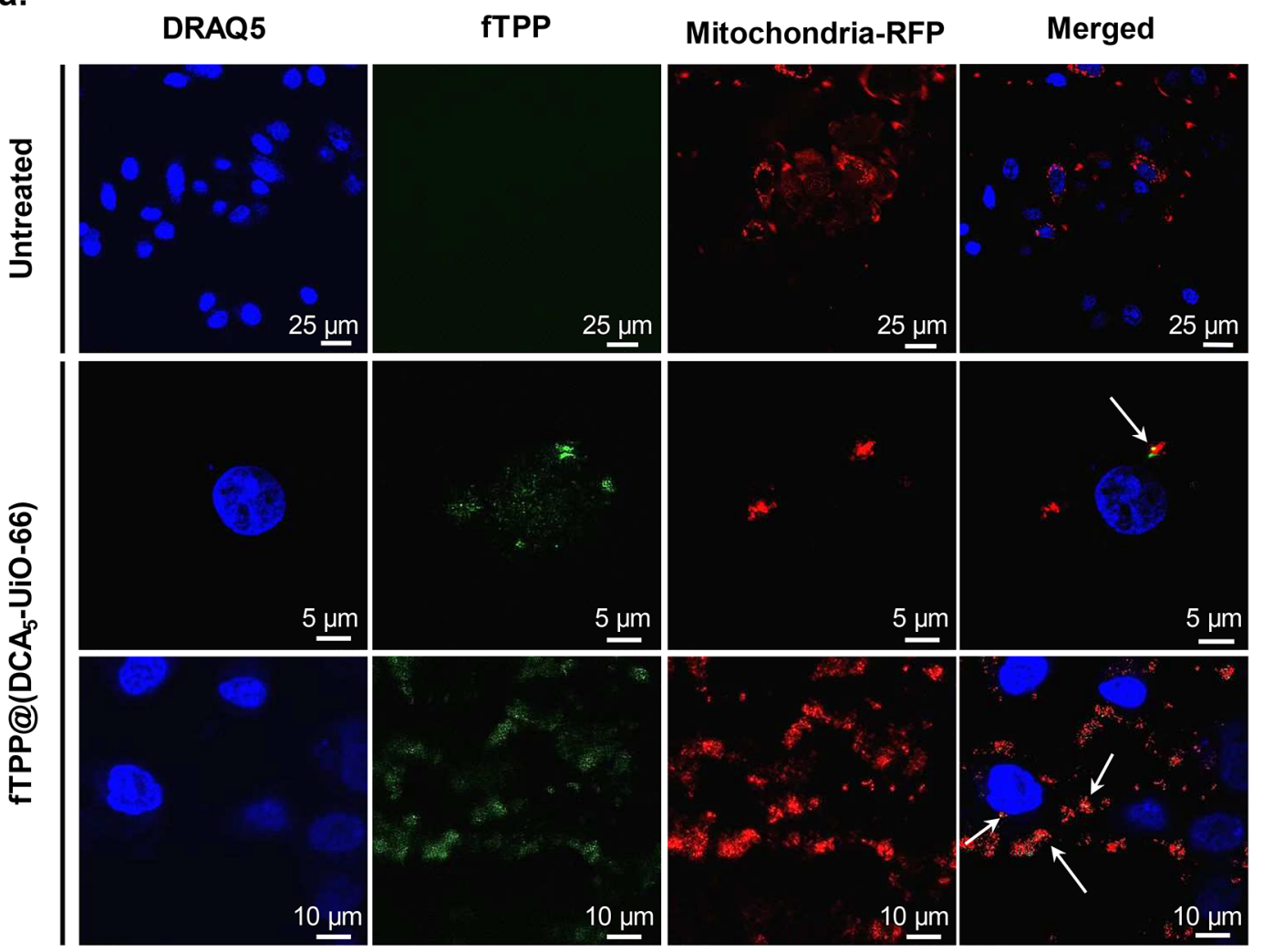

b.
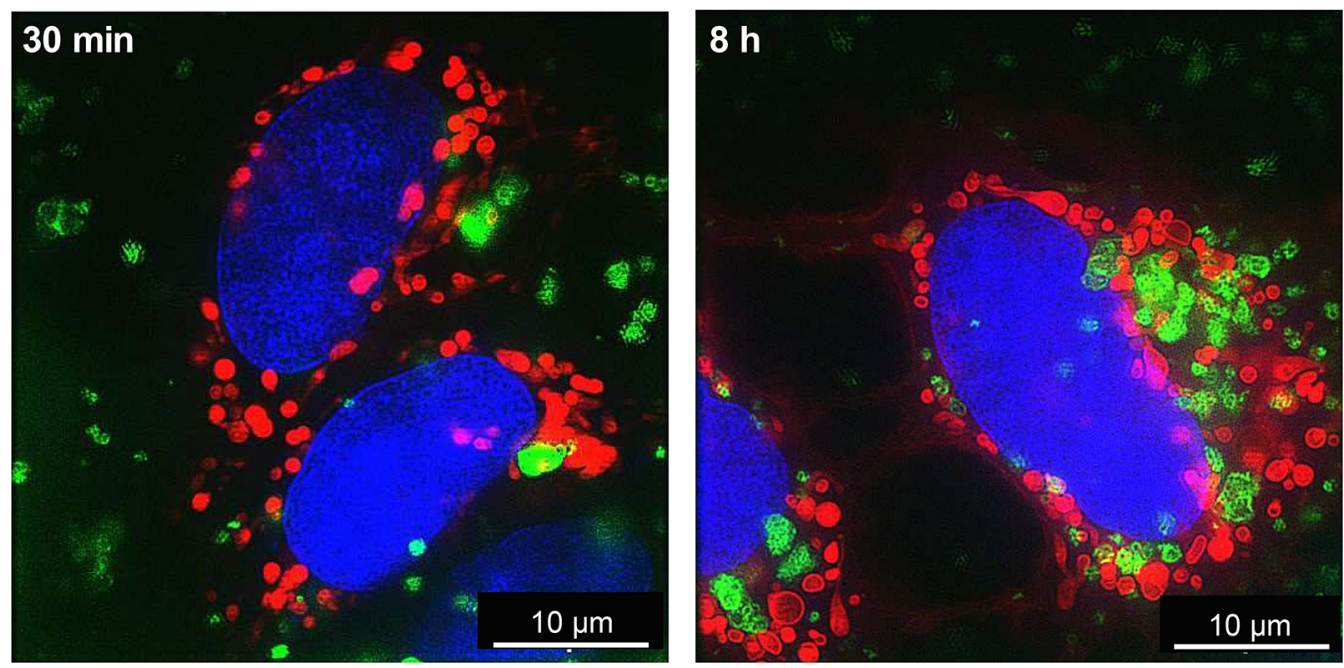

Figure 2. Microscopy imaging of MCF-7 cells. (a) Confocal microscopy images of cells incubated for $2 \mathrm{~h}$ with fTPP@(DCA $\left.-\mathrm{UiO}_{5}-66\right)$. (b) SIM images of cells incubated for $30 \mathrm{~min}$ (left) and $8 \mathrm{~h}$ (right) with cal-TPP@(DCA - -UiO-66). fTPP and calcein are shown in green, mitochondria stained with RFP are shown in red, and nuclei stained with DRAQ-5 are shown in blue. White arrows in confocal microscopy show overlap between red and green signals.

66. Whereas it is clear that the addition of TPP to the external surface dramatically increases the efficacy of the UiO-66-based DDS, its addition during the UiO-66 synthesis does not show the same benefits. This is probably because TPP loading is much lower, and it may be integrated throughout the MOF matrix and therefore cannot target the particles to the mitochondria-showing only a beneficial effect at $72 \mathrm{~h}$, perhaps due to the partial degradation and exposure of TPP to the media. This observation of the TPP located on the external surface area was confirmed by XPS, as described above.

To confirm that TPP is directing the DDS to the mitochondria, we first tracked the particles in vitro, imaging them with a modified fluorescent pyrene group on the TPP (fTPP), creating fTPP@(DCA $\left.-\mathrm{DiO}_{5}-66\right)$. Figure 2a shows the confocal images of MCF-7 cells after $2 \mathrm{~h}$ of incubation with fTPP@(DCA $-\mathrm{UiO}-66)$. Mitochondria are represented in red, and nuclei, in blue. In the merged images, we observe some colocalization between fTPP@( $\left(\mathrm{DCA}_{5}-\mathrm{UiO}-66\right)$ and RFP- 
a.

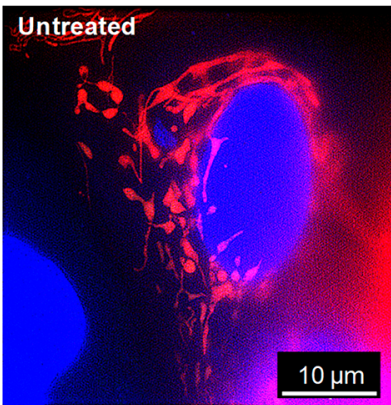

b.
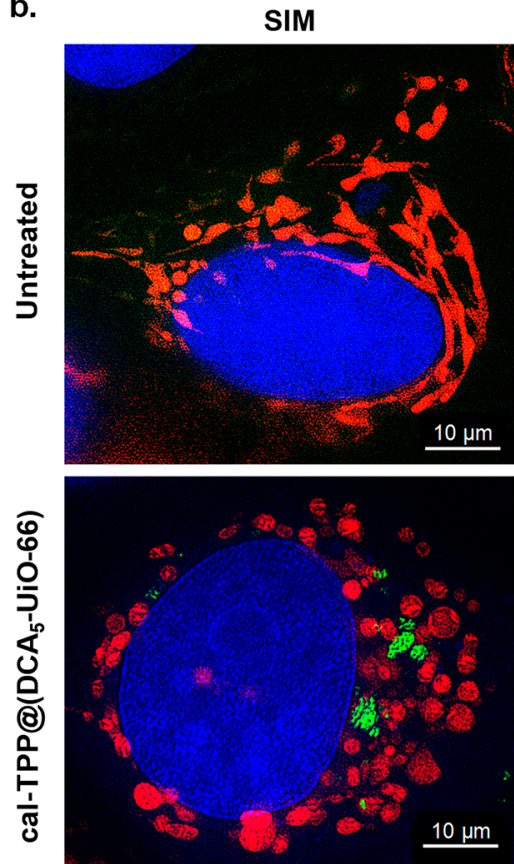

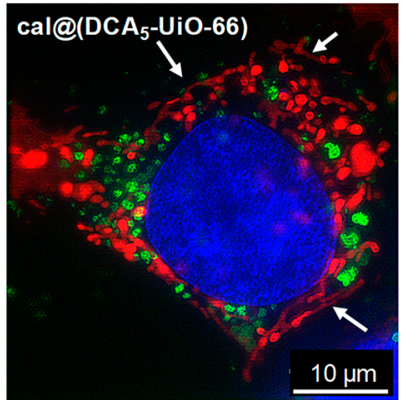

Cell Profiler representation
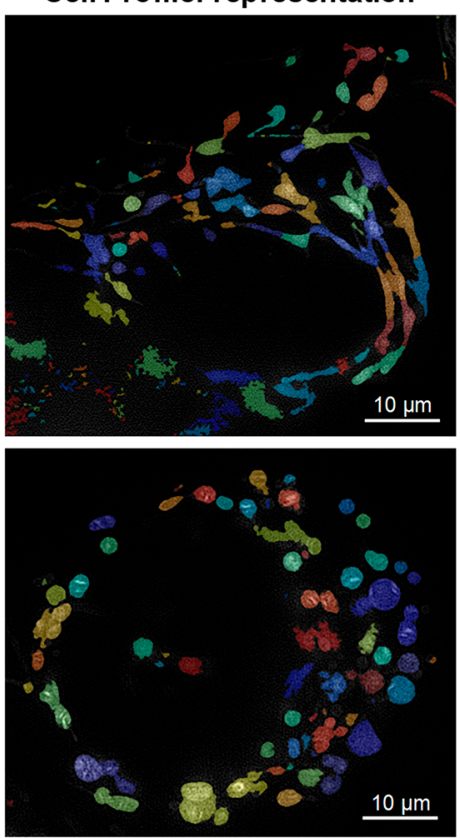

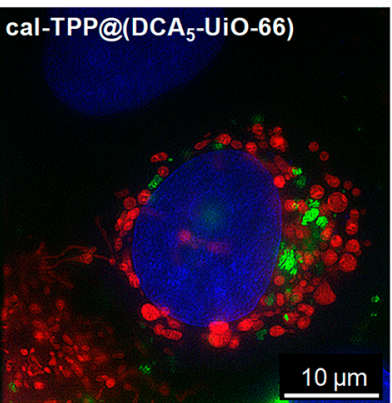

C.

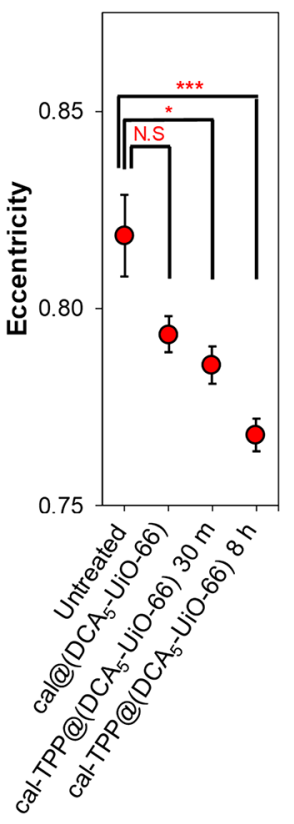

Figure 3. SIM imaging of MCF-7 cells. (a) Images of untreated cells and cells treated with cal@(DCA $\left.5-\mathrm{UiO}_{-66}\right)$ and cal-TPP@(DCA $\left.-\mathrm{UiO}_{5}-66\right)$ for $8 \mathrm{~h}$; mitochondria are colored in red, MOFs in green, and nuclei in blue; white arrows indicate stringy mitochondria. (b) Images showing a shape analysis of mitochondria using Cell Profiler software. Top row, untreated cell; bottom row, cell after 8 h of incubation with cal-TPP@(DCA $5^{-}$ UiO-66). (c) The effects of different treatments on the eccentricity of mitochondria. Results show the average eccentricity of at least 200 mitochondria. Error bars represent the standard error of the mean. Statistical significance was assessed using one-way ANOVA followed by Tukey's multiple comparisons test.

labeled mitochondria, as illustrated by the yellow color (shown by white arrows). Additionally, most of the nonoverlapping signal originating from fTPP@ $\left(\mathrm{DCA}_{5}-\mathrm{UiO}-66\right)$ is heavily concentrated around the mitochondria. This suggests that the DDS is being targeted without necessarily being completely taken up by mitochondria, possibly due to the size of the DDS being too large for mitochondrial uptake. Given the observed cytotoxic effect, mitochondrial uptake might not be necessary to observe an increase in the efficacy of DCA. The mere accumulation of particles near the mitochondria may cause high local concentrations of toxic drug.

To better visualize the internalization of the MOF and to better determine the existence of colocalization, we imaged the cells using structured illumination microscopy (SIM). Since the SIM microscope is incompatible with UV lasers, we could not use fTPP to track our system, so we loaded the MOF with the fluorescent molecule calcein instead. We named the resulting MOF cal-TPP@( $\left.\mathrm{DCA}_{5}-\mathrm{UiO}-66\right)$. Figure $2 \mathrm{~b}$ shows three-color images of cells in the presence of cal-TPP@(DCA $\mathrm{UiO}-66)$ after $30 \mathrm{~min}$ and $8 \mathrm{~h}$ incubation. These images show that the DDS is taken up by cells, as early as $30 \mathrm{~min}$ after incubation, shown by the fact that the red-colored mitochondria and green spots of MOF particles are in focus in the same plane. After $8 \mathrm{~h}$, cells take up a considerably larger amount of MOF. In terms of colocalization with the DDS, it is difficult to decipher from the images whether the MOF is distributed close to mitochondria or not. This is because mitochondria are large organelles that occupy up to $25 \%$ of the cytoplasm. However, some interesting morphological changes, which can be indicative of cellular health, ${ }^{48}$ are apparent. Whereas healthy cells are expected to have elongated mitochondria that form reticular networks, for cells treated with cal-TPP@( DCA $_{5}$ UiO-66), most mitochondria have a balloon-shaped morphology and are notably shorter in length.

To probe the effect of the targeted DDS on mitochondrial morphology further, we incubated MCF-7 cells with both targeted and nontargeted MOFs loaded with calcein. We called this new sample cal@( $\left(\mathrm{DCA}_{5}-\mathrm{UiO}-66\right)$. Figure 3a shows the SIM images of untreated and incubated cells after $8 \mathrm{~h}$. In the case of untreated cells, mitochondria are elongated and form reticular networks, as expected (Figure 3a, left). On the other hand, cells incubated with cal-TPP@( $\left.\mathrm{DCA}_{5}-\mathrm{UiO}-66\right)$ have 
short, balloon-shaped mitochondria (Figure 3a, right). For cells incubated with cal@( $\left.\mathrm{DCA}_{5}-\mathrm{UiO}-66\right)$, while mitochondria show some fragmentation, the effect is less severe than with cal-TPP@( $\left.\mathrm{DCA}_{5}-\mathrm{UiO}-66\right)$ and they still remain partially stringy and reticular, as shown by the white arrows (Figure 3a, center). Importantly, mitochondrial morphology is very dynamic by nature; depending on cellular requirements, they are recycled in a dynamic equilibrium between opposing processes of fission and fusion. ${ }^{49}$ Fusion produces extended interconnected mitochondria that form reticular networks, while fission produces shorter, balloon-shaped, fragmented mitochondria. Fission is required to control cell quality by replacing damaged mitochondria and also facilitates apoptosis during high levels of cellular stress. ${ }^{50}$ These morphological dynamics, as well as the spatial localization of mitochondria inside the cell, are heavily linked to mitochondrial and cellular function, with a good balance of fission and fusion required to maintain general cellular functionality. Kamogashira et al., for example, have demonstrated a fundamental interdependence between mitochondrial metabolic activity and its network structure. $^{50}$ The fact that fragmentation of mitochondria increases upon exposure to the targeted DDS indicates an imbalance between fission and fusion (fission $>$ fusion). Some studies $^{50,51}$ have demonstrated a direct link between mitochondrial fission and mitochondrial degradation through mitophagy - a mechanism by which impaired or damaged mitochondria are encapsulated in autophagosomes that then fuse with lysosomes where they are degraded. Interestingly, fragmentation of mitochondria-indicating mitochondrial damage-is observed as early as $30 \mathrm{~min}$ after incubation with the targeted DDS studied here (Figure $2 b$ ).

To quantify mitochondrial fragmentation, we assessed the eccentricity of each mitochondrion and assigned to it a value between 0 and 1 , with the eccentricity of a circle being 0 and that of an ellipse that is not a circle greater than 0 and less than 1. Figure $3 b$ shows representative images of the original SIM as well as of mitochondria objects identified by the Cell Profiler pipeline; Figure $3 c$ shows the quantification of the average eccentricity value for untreated cells, cells treated with calTPP@(DCA - UiO-66) for $30 \mathrm{~min}$ and $8 \mathrm{~h}$, and cells treated with cal@( $\left(\mathrm{DCA}_{5}-\mathrm{UiO}-66\right)$ for $8 \mathrm{~h}$. The value for each treatment represents the average of at least 200 mitochondria. As expected, healthy cells have the most eccentric mitochondria $(0.819 \pm 0.010)$. The larger error bars are indicative of a wide distribution of eccentricity, which is consistent with the fact that mitochondria in healthy cells have a dynamic balance between fission and fusion. Cells treated with cal@(DCA $\mathrm{UiO}-66)$ for $8 \mathrm{~h}$ have an average eccentricity of $0.793 \pm 0.005$, which is not significantly different than the untreated control. For cells treated with cal-TPP@(DCA $-\mathrm{UiO}-66)$, the eccentricity of the mitochondria is significantly reduced to $0.768 \pm$ 0.004 after $8 \mathrm{~h}(p=0.0002)$, indicating that the TPPcontaining DDS has an effect on mitochondrial morphology. Interestingly, treatment with cal-TPP@ $\left(\mathrm{DCA}_{5}-\mathrm{UiO}-66\right)$ for only $30 \mathrm{~min}$ also leads to a statistically significant change in mitochondrial eccentricity compared to untreated cells $(0.786$ $\pm 0.005 ; p=0.0267$ ), demonstrating that the system has a very rapid effect on cells. Treatment with the targeted DDS, therefore, seems to reduce mitochondrial fusion, leading to smaller mitochondrial entities, with a large number of small clusters present in the mitochondrial network attributable to the formation of autophagosomes.
To determine whether TPP@( $\left.\mathrm{DCA}_{5}-\mathrm{UiO}-66\right)$ is more toxic than $\mathrm{DCA}_{5}-\mathrm{UiO}-66$ due to a difference in cellular uptake mechanism, we studied the uptake pathway, using pharmacological inhibitors, by which MCF-7 cells take up these two MOFs. The intracellular fate of particles is dependent on the endocytosis pathway they go through, with particles taken up through clathrin-mediated endocytosis typically ending up in lysosomes where they are degraded along with their drug cargo, whereas particles going through caveolae-mediated endocytosis can sometimes be released into the cytosol and avoid lysosomal degradation. $^{28,44}$ Figure 4 a shows MCF-7 cells' internal fluorescence after incubation with the two MOFs in the presence of different endocytic inhibitors. To determine if the differences were statistically significant, we compared every value to the control at $37^{\circ} \mathrm{C}$ using ANOVA followed by Dunnett's test to adjust for multiple comparisons. When incubated at $4{ }^{\circ} \mathrm{C}$, cellular uptake of the MOFs was significantly reduced by ca. $80 \%$ for cal@ $\left(\mathrm{DCA}_{5}-\mathrm{UiO}-66\right)$ and ca. 60\% for cal-TPP@(DCA - UiO-66). Cellular metabolism is greatly slowed down at this temperature, which confirms that the particles are taken up by the active mechanism of endocytosis. When incubated with chlorpromazine (clathrin-mediated endocytosis), MOF uptake did not decrease significantly for cal@(DCA $-\mathrm{DiO}-66)$, whereas there was a moderate decrease to 69\% for cal-TPP@( DCA $_{5}-\mathrm{UiO}-$ 66). When incubated with hypertonic sucrose, particle uptake decreased significantly to 28 and 40\% for cal@( DCA $\left._{5}-\mathrm{UiO}-66\right)$ and cal-TPP@(DCA 5 -UiO-66), respectively. Although sucrose is a known inhibitor of clathrin-mediated endocytosis, there is evidence suggesting that it is nonspecific, which might explain why we observed a much larger degree of inhibition when cells were incubated with sucrose as compared to chlorpromazine. Inhibition with nystatin (caveolae-mediated endocytosis) showed no statistically significant decrease in intracellular fluorescence with respect to the controls for both DDSs. Rottlerin (macropinocytosis) significantly decreased the uptake of cal@( $\left.\mathrm{DCA}_{5}-\mathrm{UiO}-66\right)$ to $56 \%$, whereas it did not affect the uptake of cal-TPP@(DCA $-\mathrm{UiO}-66)$. These results suggest that cal@( $\left.\mathrm{DCA}_{5}-\mathrm{UiO}-66\right)$ is internalized mostly by clathrin- and caveolae- independent endocytosis, whereas cal$\mathrm{TPP} @\left(\mathrm{DCA}_{5}-\mathrm{UiO}-66\right)$ is internalized mostly by clathrindependent endocytosis. The literature offers conflicting data about the selection of endocytic pathways for charged particles. However, studies on HeLa cells using charged NPs support clathrin-mediated endocytosis for positively charged particles, ${ }^{52}$ which might explain why adding TPP to the surface of the MOF leads to this internalization route. With regard to the final intracellular fate of the particles, we have previously shown that particles taken up by clathrin-dependent endocytosis end up being degraded in lysosomes along with their cargo, voiding their therapeutic effect. ${ }^{28,44}$ However, TPP@(DCA - UiO-66) is clearly able to reach its intended target despite being taken up by clathrin-mediated endocytosis, as demonstrated by its toxicity to MCF-7 cells and the imaging studies. This could be due to the ability of positively charged TPP to act as a proton sponge and promote endosomal escape and the subsequent delivery of cargo into the cytosol.

At this point, we tested the hypothesis that the materials cause cell death by apoptosis. Dysregulation of apoptosis is a hallmark feature of most cancers, and triggering it is, therefore, an attractive target for the design of cancer treatments. A family of proteases called caspases are heavily involved in the apoptotic process. We measured the activity of caspase-3/7, 
a.

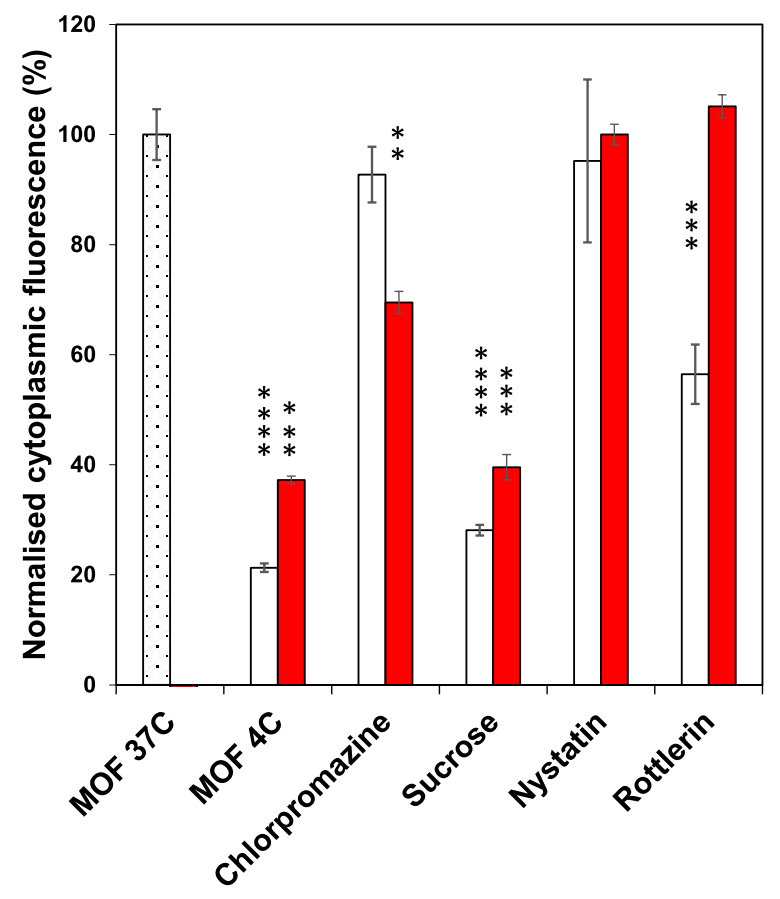

b.
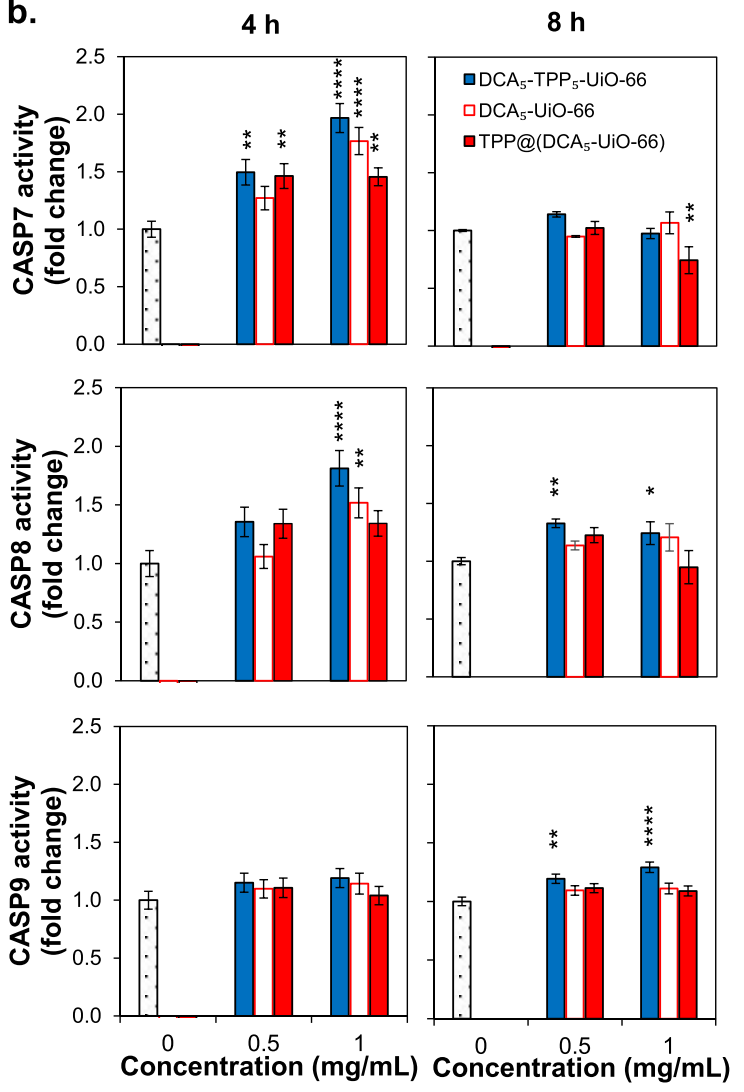

Figure 4. Final fate of MOF nanoparticles in MCF-7 cells. (a) Effects of pharmacological endocytosis inhibitors on the uptake of cal@(DCA 5 -UiO66) (white bars) and cal-TPP@(DCA $-\mathrm{DiO}_{5}$-66) (red bars) by MCF-7 cells, measured by flow cytometry. (b) Caspase 7, 8, and 9 activities after incubation of MCF-7 cells for 4 and $8 \mathrm{~h}$ with $\mathrm{DCA}_{5}-\mathrm{UiO}-66, \mathrm{DCA}_{5}-\mathrm{TPP}_{5}-\mathrm{UiO}-66$, and TPP@(DCA $\left.-\mathrm{UiO}_{5}-66\right)$. Samples were run in triplicate; error bars represent the standard error of the mean. Statistical significance was assessed using one-way ANOVA followed by Dunnett's multiple comparisons test.

caspase- 8 , and caspase- 9 after incubation with 0.5 and $1.0 \mathrm{mg} /$ $\mathrm{mL}$ of MOF for 4 and $8 \mathrm{~h}$; Figure $4 \mathrm{~b}$ shows the fold-change in caspase activity compared to untreated cells. At a concentration of $0.5 \mathrm{mg} / \mathrm{mL}$ and as early as within $4 \mathrm{~h}$, there is an increase in caspase- 7 and caspase- 8 activities for all of the TPPcontaining materials, followed by a return to baseline at $8 \mathrm{~h}$. $\mathrm{DCA}_{5}-\mathrm{UiO}-66$, which does not contain TPP, shows no increase in caspase- 7 and caspase- 8 activities at both 4 and 8 $\mathrm{h}$. There is virtually no increase in caspase- 9 activity for all four materials at 4 and $8 \mathrm{~h}$, with only $\mathrm{DCA}_{5}-\mathrm{TPP}_{5}$-UiO-66 showing a slight increase in activity after $8 \mathrm{~h}$. At a higher concentration of $1 \mathrm{mg} / \mathrm{mL}$, even TPP-absent $\mathrm{DCA}_{5}-\mathrm{UiO}-66$ causes an increase in caspase- 7 and caspase- 8 activities. It is thought that chemotherapy typically activates caspase- 9 by engaging cytochrome $\mathrm{C}$ and APAF-1 at the mitochondrial membrane, which then activates the executioner caspases $3 / 7$. However, our results suggest an important role for caspase- 8 and not for caspase-9. This has also been seen in several studies in which the roles of caspase- 8 and caspase-9, as well as the temporal and hierarchical order of the caspase events, have been questioned. For instance, Ferreira et al. demonstrated the existence of a drug-inducible apoptosis pathway in which the activation of caspase- 8 but not caspase- 9 forms the apical step from which mitochondria-dependent apoptosis occurs. ${ }^{53}$ Wieder et al. demonstrated a death-receptor-independent activation of caspase-8, slightly preceded by caspase- 3 activation, and indicating that caspase- 8 cleavage is a downstream event of postmitochondrial caspase- 3 activation. ${ }^{54}$
Pirnia et al. also demonstrated a caspase-9-independent, purely intracellular activation of caspase- 8 when treating MCF-7 cells with mitomycin C. ${ }^{55}$

Our phenotypic cell viability assays and imaging studies suggest that, by successful mitochondrial targeting via our cargo system DCA, we can enhance cellular toxicity. This cellular toxicity varies according to the differences in the design of the targeting system. To uncover the key biophysical and biochemical cellular pathways triggered by the different treatments and confirm mitochondrial involvement, we performed microarray analysis on MCF-7 cells after exposure to the treatments for $72 \mathrm{~h}$. We generated samples for microarray analysis by treating cells independently with the free drug DCA, or DCA incorporated into a MOF using three different systems: $\mathrm{DCA}_{5}-\mathrm{UiO}-66, \mathrm{DCA}_{5}-\mathrm{TPP}_{5}-\mathrm{UiO}-66$, and TPP@(DCA $\left.A_{5}-\mathrm{UiO}-66\right)$. More than 10,000 genes were detected for each comparison (Figure 5a). As expected, we did not detect any difference in the expressed genes (DEGs) when comparing cells treated with DCA to untreated cells $(p<$ 0.05 or $p<0.01)$. This indicates that DCA at a concentration of $0.25 \mathrm{mg} / \mathrm{mL}$ does not have any apparent effect on the transcriptome after 72 h, i.e., that it does not alter MCF-7 gene expression. We observed the presence of 71 DEGs $(p<0.05)$ when using $\mathrm{DCA}_{5}-\mathrm{UiO}-66$ compared to untreated cells; this number drops down to 3 DEGs when $p<0.01$. Remarkably, both mitochondrially targeted DDSs, i.e., $\mathrm{DCA}_{5}-\mathrm{TPP}_{5}-\mathrm{UiO}-66$ and TPP@( $\left.\mathrm{DCA}_{5}-\mathrm{UiO}-66\right)$, induced drastic widespread changes in gene expression profiles. $\mathrm{DCA}_{5}-\mathrm{TPP}_{5}$-UiO-66 


\begin{tabular}{cccc}
\hline $\begin{array}{c}\text { Comparison of } \\
\text { untreated vs. }\end{array}$ & $\mathbf{p}<0.05$ & $\mathbf{p}<0.01$ & $\begin{array}{c}\text { Genes } \\
\text { detected }\end{array}$ \\
\hline free DCA & 0 & 0 & 10702 \\
$\mathrm{DCA}_{5}$-UiO-66 & 70 & 3 & 10693 \\
$\mathrm{TPP} @\left(\mathrm{DCA}_{5}\right.$-UiO-66) & 910 & 358 & 10725 \\
$\mathrm{DCA}_{5}-\mathrm{TPP}_{5}$-UiO-66 & 1519 & 465 & 10691 \\
\hline
\end{tabular}

b.

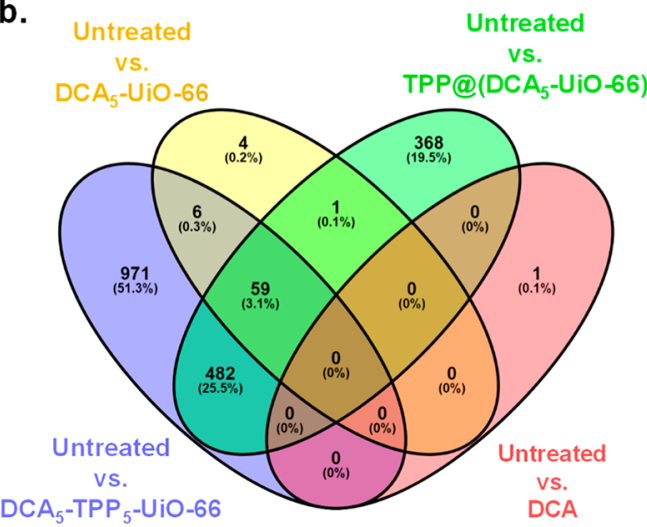

C.

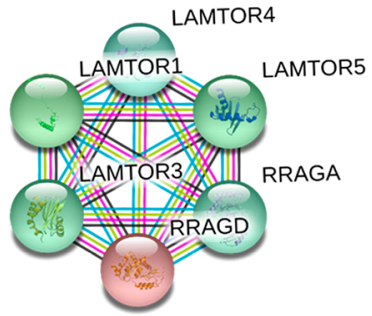

d.
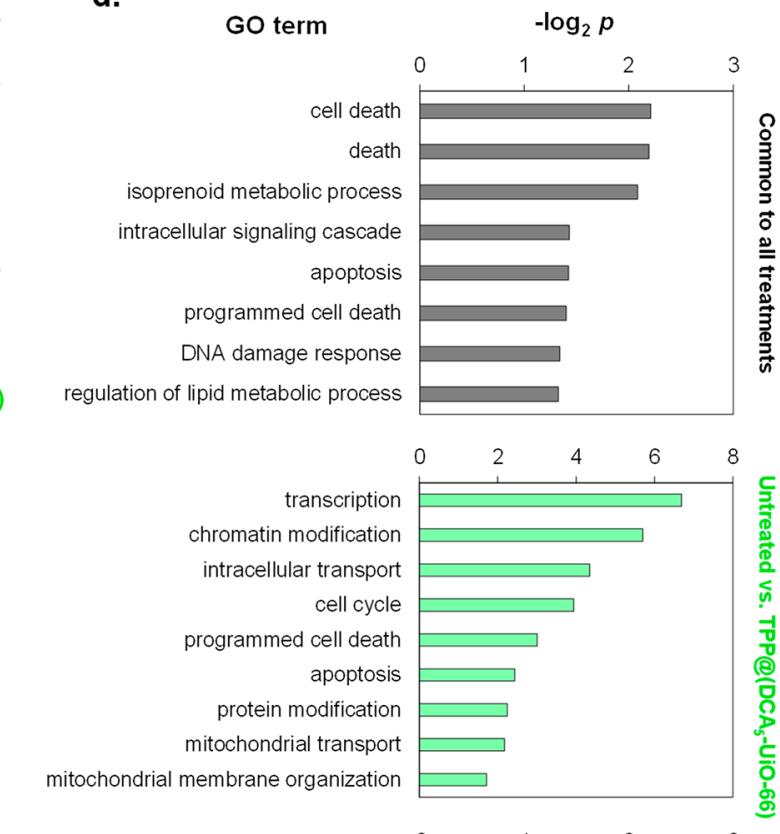

regulation of transcription, DNA-dependen regulation of caspase activity regulation of peptidase activity

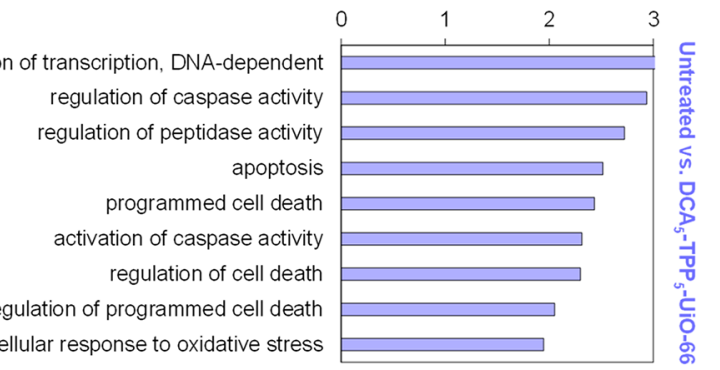

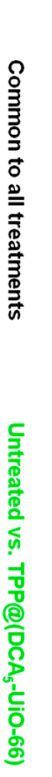

Figure 5. Biochemical effects of different treatments on MCF-7 cells. (a) Number of differentially expressed genes between cells treated with different conditions. (b) Venn diagram analysis of differentially expressed genes in microarrays of MCF-7 cells treated with DCA $5^{-}$UiO-66, DCA $_{5}-$ TPP - -UiO-66, and TPP@(DCA5-UiO-66) compared to untreated control. (c) Gene network displaying interconnected genetic targets in common for all three treatments. (d) Significant gene ontology (GO) terms of associated biological processes from 59 differentially expressed genes $(p<$

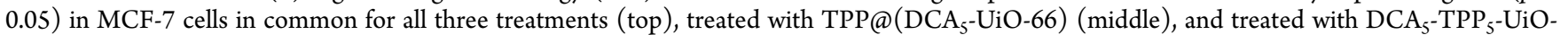
66 (bottom).

caused significant changes in the expression level of 1519 genes $(p<0.05)$, of which 821 were up-regulated and 698 were down-regulated, and TPP@(DCA $-\mathrm{UiO}-66)$ affected the expression level of 910 genes $(p<0.05)$, of which 533 were up-regulated and 377 were down-regulated. These results are consistent with the efficacy of these drugs that we observed in our cell viability assays where we found most toxicity in cells treated with $\mathrm{DCA}_{5}-\mathrm{TPP}_{5}-\mathrm{UiO}-66$ and TPP@(DCA $\left.-\mathrm{UiO}-66\right)$.

Since the core component of our synthesized drug delivery systems is DCA, which varies in its efficacy due in part to the attached targeting agent, we performed Venn diagram analysis at $p<0.05$ to find gene targets which are common as well as exclusive to different treatments (Figure $5 \mathrm{~b}$ ). We found that 59 gene targets were common to treatments with $\mathrm{DCA}_{5}-\mathrm{UiO}-66$, $\mathrm{DCA}_{5}-\mathrm{TPP}_{5}-\mathrm{UiO}-66$, and TPP@(DCA $\left.-\mathrm{UiO}-66\right)$. These 59 genes represented $84 \%$ of the genes differentially expressed by $\mathrm{DCA}_{5}-\mathrm{UiO}-66$, with $\mathrm{DCA}_{5}-\mathrm{TPP}_{5}-\mathrm{UiO}-66$ and TPP@(DCA UiO-66) affecting numerous additional genes (1460 and 851, respectively). This supports the results showing that the addition of TPP to the MOF increases the efficacy of DCA on MCF-7 cells. Figure 5d shows a gene ontology (GO) analysis of the differentially expressed genes in MCF-7 after the different treatments. Consistent with our phenotypic observations, analysis of the 59 common gene targets revealed the significant enrichment of GO terms such as cell death, apoptosis, and programmed cell death. Since the efficacy of $\mathrm{DCA}_{5}-\mathrm{TPP}_{5}-\mathrm{UiO}-66$ and TPP@(DCA $\left.-\mathrm{UiO}-66\right)$ was much higher than that of $\mathrm{DCA}_{5}-\mathrm{UiO}-66$, we analyzed the gene targets that were exclusive to $\mathrm{DCA}_{5}-\mathrm{TPP}_{5}-\mathrm{UiO}-66$ or TPP@(DCA $-\mathrm{UiO}-66)$. GO analysis of the exclusive targets revealed the significant enrichment of biological processes, which have a more profound effect on cell physiology, such as transcription, chromatin modification, regulation of caspase activity, and oxidative stress, although it is difficult to pinpoint exactly how much each component of the DDS participates in each effect with the current experimental setup. Interestingly, we also found significant enrichment of biological processes such as mitochondrial transport and mitochondrial membrane organization for the treatment with TPP@( $\left.\mathrm{DCA}_{5}-\mathrm{UiO}-66\right)$, the most toxic system to cells. Next, we explored if there is any gene network, underlying the regulation of cell proliferation and survival, upregulated in cells treated with drugs. By using the STRING program, ${ }^{56}$ we performed functional protein association network analysis with all of the genes that were significantly upregulated in cells treated with either of the drugs (Figure S8) and extrapolated this network with the genes which have been reported to be functionally associated with the genes in our list. We identified a gene network (Figure 5c), 
common to all three treatments, which is a part of the mTOR signaling pathway, the master regulator of cell metabolism, growth, and survival. This gene network could be built mainly because of the gene RRAGD, a G protein which is crucial in activating the mTOR signaling cascade, which was commonly targeted by all three drugs. Taken together, our microarray analysis complements our phenotypic assays and consolidates our drug design strategy for successful targeting of mitochondria.

\section{OUTLOOK}

We have demonstrated the successful development of a mitochondria-targeted metal-organic framework that greatly increases the efficacy of the anticancer agent DCA. This targeting effect is important for novel cancer treatments due to the key role of mitochondria in oncogenesis. In vitro viability studies suggest that targeting the delivery system to mitochondria greatly reduces the amount of the required drug to less than $1 \%$ compared to the free drug and ca. $10 \%$ compared to the nontargeted system. We have used a number of cutting-edge techniques to elucidate the biophysical and biochemical mechanisms of cell death. Using super-resolution microscopy, we demonstrate that the targeted MOF localizes around mitochondria, causing morphological changes associated with toxicity when incubated with the mitochondriatargeted system-as soon as 30 min after treatment-that can be observed in unprecedented detail. Cellular uptake studies showed no uptake through the caveolae-mediated route, suggesting an endolysosomal route to degradation within the cell. The observed toxicity of the targeted system is nonetheless indicative of its ability to escape endosomes and reach mitochondria, something that could be attributed to the TPP acting as a proton sponge and allowing the rupture of endosomes. We then studied the changes in gene expression after treatment with the targeted MOF using a wholetranscriptome analysis; we used a microarray analysis on MCF-7 cells to examine the key biophysical and biochemical pathways triggered by the delivery systems, where we found widespread changes in gene expression. Key pathways affected are biological processes having a profound effect on cell growth, metabolism, and survival. This work allowed us to uncover the effects of MOF-based delivery systems at the transcriptional level, validating observations seen at the functional level. Through this work, we show how the efficacy of existing drugs can be dramatically improved using this highly tunable material; our holistic approach uncovers the potential of MOF-based DDSs and fundamentally justifies their benefits as materials that can greatly enhance the therapeutic efficacy of drugs. Thinking globally, we propose this work to serve as a guideline for the exploration of future, targeted drug delivery vehicles.

\section{METHODS}

Materials. $\mathrm{ZrCl}_{4}$ (99.5\%) and terephthalic acid (BDC, 98\%) were purchased from Alfa Aesar (U.K.). Dichloroacetic acid ( $\geq 99 \%), \mathrm{HCl}$ (37\%), 4-carboxybutyl triphenylphosphonium bromide (98\%), 3(diphenylphosphino)propionic acid (97\%), 1-bromopyrene (96\%), acetic acid ( $\geq 99 \%)$, dimethylformamide (DMF, 99.8\%), methanol (99.9\%), and acetone (99.9\%) were purchased from Sigma-Aldrich (U.K.). Dulbecco's modified Eagle's medium (DMEM), fetal bovine serum (FBS), L-glutamine, penicillin, streptomycin, and CellLight Mitochondria-GFP BacMam 2.0 were purchased from Invitrogen (U.K.). The DRAQ5 stain was purchased from Abcam. Phosphatebuffered saline (PBS), trypsin-EDTA, and Lysotracker-Deep Red were purchased from Life Technologies (U.K.). CellTiter 96 AQueous One Solution Cell Proliferation Assay (MTS) and Caspase-Glow 3/7, 8, and 9 Assay Systems were obtained from Promega (U.K.). All chemicals and biochemicals used were of analytical grade. MCF-7 (ECACC 86012803) and HEK293 (ECACC 85120602 ) cells were obtained from the ECACC.

Synthesis of $\mathrm{DCA}_{5}-\mathrm{TPP}_{5}-\mathrm{UiO}-66$. A $10 \mathrm{~mL}$ portion of a DMF solution containing BDC $(149.6 \mathrm{mg}, 0.9 \mathrm{mmol})$ and TPP $(1995 \mathrm{mg}$, $4.5 \mathrm{mmol}$ ) was added to $10 \mathrm{~mL}$ of a DMF solution containing $\mathrm{ZrCl}_{4}$ $(209.6 \mathrm{mg}, 0.9 \mathrm{mmol})$ in a $25 \mathrm{~mL}$ glass vial. $\mathrm{HCl}(80 \mu \mathrm{L}, 0.9 \mathrm{mmol})$ and DCA $(275 \mu \mathrm{L}, 4.5 \mathrm{mmol})$ were added to the mixture. Next, the vials were sealed and put in an oven at $120^{\circ} \mathrm{C}$ for $24 \mathrm{~h}$. The resulting powders were collected by centrifugation $(5500 \mathrm{rpm}, 15 \mathrm{~min})$ and redispersed in $10 \mathrm{~mL}$ of $\mathrm{DMF}$, followed by another centrifugation cycle. This two-step washing process was repeated two more times with DMF to remove the unreacted $\mathrm{BDC}$, followed by two washes with methanol to remove the DMF. The collected UiO-66 particles were finally dried at room temperature under a vacuum overnight. The amounts of DCA and TPP incorporated in the structure were determined by ICP-OES.

Synthesis of fTPP. Synthesis of fTPP was done according to a previously published protocol. ${ }^{37}$ 1-Bromopyrene (1744 mg, 5.92 $\mathrm{mmol}$ ) and 3-(diphenylphosphino)propionic acid (2296 mg, 8.88 $\mathrm{mmol}$ ) were dissolved in $64 \mathrm{~mL}$ of toluene and were then left to reflux overnight. The resulting yellow precipitate was hot-filtered, washed once with methanol, and then left to dry in a rotary evaporator, giving rise to a pale yellow solid ( $3.223 \mathrm{~g}, 98 \%$ ).

Postsynthetic Attachment of TPP to UiO-66-DCA. A $40 \mathrm{mg}$ portion of UiO-66-DCA was dispersed in $20 \mathrm{~mL}$ of methanol and sonicated for $5 \mathrm{~min}$. Separately, $40 \mathrm{mg}$ of either 4-carboxybutyl-TPP or fTPP was dissolved in $20 \mathrm{~mL}$ of $\mathrm{MeOH}$, and $0.2 \mathrm{~mL}$ of triethylamine was added to the mixture. The two solutions were then mixed and left to stir at room temperature overnight. The nanoparticles were collected by centrifugation, washed $(\times 2)$ with methanol to wash off unattached TPP, and left to dry under a vacuum at room temperature overnight.

Powder X-ray Diffraction (PXRD). PXRD measurements were carried out at $298 \mathrm{~K}$ using a PANalytical X'Pert PRO diffractometer $(\lambda(\mathrm{Cu} \mathrm{K} \alpha)=1.5418 \AA)$ on a mounted bracket sample stage. Data were collected over the range $5-45^{\circ}$.

Thermogravimetric Analysis (TGA). Measurements were carried out using a TA Instruments Q500 Thermogravimetric Analyzer. Measurements were collected from room temperature to $800{ }^{\circ} \mathrm{C}$ with a heating rate of $10^{\circ} \mathrm{C} / \mathrm{min}$ under an air atmosphere.

Dynamic Light Scattering. Colloidal analysis was performed by dynamic light scattering (DLS) with a Zetasizer Nano ZS potential analyzer equipped with NonInvasive Backscatter optics (NIBS) and a $50 \mathrm{~mW}$ laser at $633 \mathrm{~nm}$.

ICP-OES. Zirconium, chlorine, and phosphorus quantification was performed on a Thermo Scientific iCAP 7400 ICP-OES analyzer against 1 and 10 ppm standards.

Nuclear Magnetic Resonance (NMR) Spectroscopy. NMR spectra were recorded on either a Bruker AVIII $400 \mathrm{MHz}$ spectrometer or a Bruker AVI $500 \mathrm{MHz}$ spectrometer and referenced to residual solvent peaks.

UV-vis/Fluorescence Spectroscopy. UV-vis and fluorescence spectra were recorded using a Tecan Spark Multimode Microplate Reader.

Scanning Electron Microscopy (SEM). The powder samples were coated with Pd for $150 \mathrm{~s}$ using a Polaron SC7640 sputter coater and imaged using a Carl Zeiss Sigma Variable Pressure Analytical SEM with Oxford Microanalysis.

Transmission Electron Microscopy (TEM). TEM measurements were carried out on a FEI TECNAI F20 instrument with an acceleration voltage of $200 \mathrm{kV}$. Samples were prepared by dropcasting a sonicated methanolic suspension on a 400 mesh $\mathrm{Cu}$ grid.

X-ray Photoelectron Spectra (XPS). Measurements were performed with a K-ALPHA spectrometer (Thermo Fisher Scientific, Waltham, MA, USA) operated in the constant energy mode with survey pass energies of $200 \mathrm{eV}$ and narrow scan energies of $50 \mathrm{eV}$, to 
measure the whole energy band as well as selectively measure particular elements. XPS spectra were acquired using $\mathrm{Al} \mathrm{K} \alpha$ radiation $(1486.6 \mathrm{eV})$ with a twin monochromator, yielding a focused X-ray spot at $3 \mathrm{~mA} \times 12 \mathrm{kV}$. Charge compensation was attained with the system flood gun, which provides low energy electrons and low energy argon ions from a single source. For the reference binding energy, the C 1 s core level was used, located at $284.6 \mathrm{eV}$.

Confocal Microscopy. Measurements were carried out using a Leica TCS SP5 confocal microscope. The microscope was equipped with 405 diode, argon, and HeNe lasers. Leica LAS AF software was used to analyze the images.

Super-Resolution Microscopy. Measurements were carried out using a custom-built three-color structured illumination microscopy (SIM) setup that has been described previously. ${ }^{57}$ The structured illumination patterns were generated by a spatial light modulator (SLM: SXGA-3DM, Forth Dimension Displays). A $60 \times / 1.2$ NA water immersion lens (UPLSAPO 60XW, Olympus) focused the structure illumination pattern onto the sample. This lens also captured the fluorescence emission from the sample, which was imaged onto a sCMOS camera (C11440 Hamamatsu). Laser excitation wavelengths used were $488 \mathrm{~nm}$ (iBEAM-SMART-488, Toptica), $561 \mathrm{~nm}$ (OBIS 561, Coherent), and $640 \mathrm{~nm}$ (MLD 640, Cobolt), to excite the fluorescence emission of MOF, mitochondria, and DNA, respectively. Images were acquired using custom SIM software previously published. ${ }^{57}$ Nine raw images were collected at each plane and recombined using a custom implementation of the fairSIM algorithm. ${ }^{58}$

Cell Culture. MCF- 7 cells were cultured at $37{ }^{\circ} \mathrm{C}$ with $5 \% \mathrm{CO}_{2}$ in highly rich glucose $(4500 \mathrm{mg} / \mathrm{L})$ DMEM with phenol red supplemented with $10 \%(v / v)$ FBS, $2 \mathrm{mM}$ L-glutamine, 100 units/ $\mathrm{mL}$ penicillin, and $100 \mu \mathrm{g} / \mathrm{mL}$ streptomycin. This was named complete DMEM (cDMEM). The cells were passaged three times a week, whenever the cells reached $70-80 \%$ confluency.

Cytotoxicity Assays. MCF-7 cells were seed in 96-well plates at a density of 7500 cells/well and were cultured at $37{ }^{\circ} \mathrm{C}$ with $5 \% \mathrm{CO}_{2}$ for $24 \mathrm{~h}$.

MTS Viability Assay. The concentration- and time-dependent viability of cells in the presence of $\mathrm{DCA}_{x}-\mathrm{UiO}-66, \mathrm{DCA}_{5}-\mathrm{TPP}_{5}-\mathrm{UiO}$ 66, TPP@(DCA - -UiO-66), TPP, and DCA was investigated using the CellTiter 96 Aqueous Non-Radioactive Cell Proliferation Assay (Promega, U.K.). The day after seeding the cells, the different MOFs and drugs were dispersed in complete medium and a range of concentrations was prepared $(0-1 \mathrm{mg} / \mathrm{mL})$, of which $100 \mu \mathrm{L}$ were added to each well and incubated for $4-72 \mathrm{~h}$ at $37^{\circ} \mathrm{C}$ with $5 \% \mathrm{CO}_{2}$. At the end of the incubation period, the treatment solutions were removed. The cells were washed once with PBS, and then, $100 \mu \mathrm{L}$ of fresh growth media was added to each well. To measure the toxicity, $20 \mu \mathrm{L}$ of MTS solution was added to each well. The plate was then covered with aluminum foil and placed at $37{ }^{\circ} \mathrm{C}$ and $5 \% \mathrm{CO}_{2}$ for 75 min. Then, $100 \mu \mathrm{L}$ of solution from each well was transferred to a new 96-well plate. The plate was read by UV/vis spectroscopy.

Caspase Activity. Caspase 3/7, 8, and 9 activity in the presence of DCA $_{5}-\mathrm{UiO}-66, \mathrm{TPP} @\left(\mathrm{DCA}_{5}-\mathrm{UiO}-66\right)$, and $\mathrm{DCA}_{5}-\mathrm{TPP}_{5}-\mathrm{UiO}-66$ was assessed using the Caspase-Glow assay system (Promega, U.K.). Cells were incubated in the presence of varying concentrations of MOF at 4 and $8 \mathrm{~h}$. Caspase activity was then assessed according to the manufacturer's instructions using a TECAN Spark microplate reader. Experiments were done in quintuplicate.

Co-Localization with Mitochondria. Cells were seeded at 100,000 cells/well in a four-well chambered cell culture cover glass and left to grow for $24 \mathrm{~h}$. They were then transfected with CellLight Mitochondria-GFP BacMam 2.0 and left to incubate overnight. The cells were then incubated with fTPP@(DCA $-\mathrm{UiO}-66)$ for $2 \mathrm{~h}$, after which the media was removed, and the wells washed twice with PBS. Five $\mu \mathrm{M}$ of DRAQ5 solution in media was added to the cells and left to incubate at room temperature in the dark for 5-30 min. The cells were then analyzed directly without further washing using a TCS SP5 inverted laser scanning microscope (Leica, Germany). An argon laser was used to visualize GFP-stained mitochondria (excitation at $488 \mathrm{~nm}$ and emission filter set at 505-555 nm). To visualize the stained nucleus, a helium-neon laser was used (excitation at $633 \mathrm{~nm}$ and emission filter set at 650-700 nm). fTPP@(DCA 5 -UiO-66) was excited using a diode laser emitting at $405 \mathrm{~nm}$. Images were taken sequentially. Fluorescent images of cells were acquired as described above. Images were then merged and converted to 8-bit RGB format using ImageJ software.

Mitochondrial Morphology Study. Cells were seeded at 100,000 cells/well in a four-well chambered cell culture cover glass and left to grow for $24 \mathrm{~h}$. They were then transfected with CellLight Mitochondria-GFP BacMam 2.0 and left to incubate overnight. The cells were then incubated with cal@ $\left(\mathrm{DCA}_{5}-\mathrm{UiO}-66\right)$ or calTPP@(DCA - -UiO-66) for $30 \mathrm{~min}$ and $8 \mathrm{~h}$, after which the media was removed, and the wells washed twice with PBS. Five $\mu \mathrm{M}$ of DRAQ5 solution in media was added to the cells and left to incubate at room temperature in the dark for 5-30 $\mathrm{min}$. The cells were then analyzed directly without further washing using the three-color structured illumination microscope (SIM) setup described above. Mitochondria eccentricity was assessed using a custom-designed pipeline for Cell Profiler. ${ }^{59}$ Briefly, the tool performed the following actions: Extract the mitochondria channel from the central slice of the reconstructed SIM image; apply a median filter window size of 7 to remove elements of noise; run the "IdentifyPrimaryObjects" plugin to extract mitochondria as objects from the image; run the "MeasureObjectSizeShape" plugin to gather statistics on detected objects; filter objects with an area less than 20 pixels $\left(34 \mu \mathrm{m}^{2}\right)$; export filtered mitochondria objects to a spreadsheet. The eccentricity column was exported from the spreadsheet for further statistical analysis. The one-way ANOVA test was performed using GraphPad Prism version 7.04 for Windows to assess the statistical difference of mitochondria eccentricity between different experimental conditions.

\section{ASSOCIATED CONTENT}

\section{Supporting Information}

The Supporting Information is available free of charge at https://pubs.acs.org/doi/10.1021/jacs.0c00188.

Further information on materials synthesis and characterization, in vitro control experiments, cytotoxicity, and transcriptomics (PDF)

\section{AUTHOR INFORMATION}

\section{Corresponding Authors}

Gabriele S. Kaminski Schierle - Molecular Neuroscience Group, Department of Chemical Engineering \& Biotechnology, University of Cambridge, Cambridge CB3 OAS, U.K.; ○ orcid.org/0000-0002-1843-2202; Email: gsk20@ cam.ac.uk

Clemens F. Kaminski - Laser Analytics Group, Department of Chemical Engineering \& Biotechnology, University of Cambridge, Cambridge CB3 OAS, U.K.; (1) orcid.org/00000002-5194-0962; Email: cfk23@cam.ac.uk

Ross S. Forgan - WestCHEM School of Chemistry, University of Glasgow, Glasgow G12 8QQ, U.K.; 이이이.org/00000003-4767-6852; Email: ross.forgan@glasgow.ac.uk

David Fairen-Jimenez - Adsorption \& Advanced Materials Laboratory (AAML), Department of Chemical Engineering \& Biotechnology, University of Cambridge, Cambridge CB3 OAS, U.K.; @ orcid.org/0000-0002-5013-1194; Email: df334@ cam.ac.uk

\section{Authors}

Salame Haddad - Adsorption \& Advanced Materials Laboratory (AAML), Department of Chemical Engineering \& Biotechnology, University of Cambridge, Cambridge CB3 OAS, U.K. 
Isabel Abánades Lázaro - WestCHEM School of Chemistry, University of Glasgow, Glasgow G12 8QQ, U.K.

Marcus Fantham - Laser Analytics Group, Department of Chemical Engineering \& Biotechnology, University of Cambridge, Cambridge CB3 OAS, U.K.

Ajay Mishra - Cambridge Infinitus Research Centre, Department of Chemical Engineering \& Biotechnology, University of Cambridge, Cambridge CB3 OAS, U.K.

Joaquin Silvestre-Albero - Laboratorio de Materiales Avanzados, Departamento de Química Inorgánica-Instituto Universitario de Materiales, Universidad de Alicante, E-03690 San Vicente del Raspeig, Spain; 이이이.org/0000-0002-03030817

Johannes W. M. Osterrieth - Adsorption \& Advanced Materials Laboratory (AAML), Department of Chemical Engineering \& Biotechnology, University of Cambridge, Cambridge CB3 OAS, U.K.; 이이이.org/0000-0002-4724$901 X$

Complete contact information is available at: https://pubs.acs.org/10.1021/jacs.0c00188

\section{Notes}

The authors declare no competing financial interest.

\section{ACKNOWLEDGMENTS}

This project has received funding from the European Research Council (ERC) under the European Union's Horizon 2020 research and innovation programme (NanoMOFdeli), ERC2016-COG 726380, and (SCoTMOF), ERC-2015-STG677289. D.F.-J. and R.S.F. thank the Royal Society for funding through University Research Fellowships. C.F.K. acknowledges funding from the UK Engineering and Physical Sciences Research Council, EPSRC (grants EP/L015889/1 and EP/ H018301/1), the Wellcome Trust (grants 3-3249/Z/16/Z and 089703/Z/09/Z) and the UK Medical Research Council, MRC (grants MR/K015850/1 and MR/K02292X/1), and Infinitus (China) Ltd. We thank EPSRC (grant EP/S009000/ 1).

\section{REFERENCES}

(1) Porporato, P. E.; Filigheddu, N.; Pedro, J. M. B.-S.; Kroemer, G.; Galluzzi, L. Mitochondrial Metabolism and Cancer. Cell Res. 2018, 28 (3), 265-280.

(2) Voet, D.; Voet, J. G.; Pratt, C. W. Fundamentals of Biochemistry, 2nd ed.; John Wiley and Sons: 2006.

(3) Alkarakooly, Z.; Kilaparty, S. P.; Al-Anbaky, Q. A.; Khan, M. S.; Ali, N. Dichloroacetic Acid (DCA)-Induced Cytotoxicity in Human Breast Cancer Cells Accompanies Changes in Mitochondrial Membrane Permeability and Production of Reactive Oxygen Species. J. Cancer Ther. 2014, 5, 1234-1248.

(4) Fulda, S. Tumor Resistance to Apoptosis. Int. J. Cancer 2009, 124 (3), 511-515.

(5) Hanahan, D.; Weinberg, R. A. The Hallmarks of Cancer. Cell 2000, 100 (1), 57-70.

(6) Armstrong, J. S. Mitochondrial Medicine: Pharmacological Targeting of Mitochondria in Disease. Br. J. Pharmacol. 2007, 151 (8), $1154-1165$.

(7) Galluzzi, L.; Larochette, N.; Zamzami, N.; Kroemer, G. Mitochondria as Therapeutic Targets for Cancer Chemotherapy. Oncogene 2006, 25 (34), 4812-4830.

(8) Gogvadze, V.; Orrenius, S.; Zhivotovsky, B. Mitochondria as Targets for Cancer Chemotherapy. Semin. Cancer Biol. 2009, 19 (1), $57-66$.
(9) Kroemer, G.; Pouyssegur, J. Tumor Cell Metabolism: Cancer's Achilles' Heel. Cancer Cell 2008, 13 (6), 472-482.

(10) Pathak, R. K.; Kolishetti, N.; Dhar, S. Targeted Nanoparticles in Mitochondrial Medicine. Wiley Interdiscip. Rev.: Nanomed. Nanobiotechnol. 2015, 7 (3), 315-329.

(11) He, C.; Liu, D.; Lin, W. Nanomedicine Applications of Hybrid Nanomaterials Built from Metal-Ligand Coordination Bonds: Nanoscale Metal-Organic Frameworks and Nanoscale Coordination Polymers. Chem. Rev. 2015, 115 (19), 11079-11108.

(12) Miller, S. E.; Teplensky, M. H.; Moghadam, P. Z.; Fairenjimenez, D. Metal-Organic Frameworks as Biosensors for Luminescence-Based Detection and Imaging. Interface Focus 2016, 6, 20160027.

(13) Della Rocca, J.; Liu, D.; Lin, W. Nanoscale Metal-Organic Frameworks for Biomedical Imaging and Drug Delivery. Acc. Chem. Res. 2011, 44 (10), 957-968.

(14) Teplensky, M. H.; Fantham, M.; Li, P.; Wang, T. C.; Mehta, J. P.; Young, L. J.; Moghadam, P. Z.; Hupp, J. T.; Farha, O. K.; Kaminski, C. F.; Fairen-Jimenez, D. Temperature Treatment of Highly Porous Zirconium-Containing Metal-Organic Frameworks Extends Drug Delivery Release. J. Am. Chem. Soc. 2017, 139 (22), $7522-7532$.

(15) Wu, M. X.; Yang, Y. W. Metal-Organic Framework (MOF)Based Drug/Cargo Delivery and Cancer Therapy. Adv. Mater. 2017, 29 (23), 1606134.

(16) Abanades-Lazaro, I.; Haddad, S.; Sacca, S.; Orellana-Tavra, C.; Fairen-Jimenez, D.; Forgan, R. S. Selective Surface PEGylation of UiO-66 Nanoparticles for Enhanced Stability, Cell Uptake, and $\mathrm{pH}$ Responsive Drug Delivery. Chem. 2017, 2, 561-578.

(17) Orellana-Tavra, C.; Baxter, E. F.; Tian, T.; Bennett, T. D.; Slater, N. K. H.; Cheetham, A. K.; Fairen-Jimenez, D. Amorphous Metal-Organic Frameworks for Drug Delivery. Chem. Commun. 2015, 51 (73), 13878-13881.

(18) Moghadam, P. Z.; Li, A.; Wiggin, S. B.; Tao, A.; Maloney, A. G. P.; Wood, P. A.; Ward, S. C.; Fairen-Jimenez, D. Development of a Cambridge Structural Database Subset: A Collection of MetalOrganic Frameworks for Past, Present, and Future. Chem. Mater. 2017, 29, 2618-2625.

(19) Simon-Yarza, M. T.; Baati, T.; Paci, A.; Lesueur, L. L.; Seck, A.; Chiper, M.; Gref, R.; Serre, C.; Couvreur, P.; Horcajada, P. Antineoplastic Busulfan Encapsulated in a Metal Organic Framework Nanocarrier: First in Vivo Results. J. Mater. Chem. B 2016, 4, 585588.

(20) He, C.; Lu, K.; Liu, D.; Lin, W. Nanoscale Metal-Organic Frameworks for the Co-Delivery of Cisplatin and Pooled SiRNAs to Enhance Therapeutic Efficacy in Drug-Resistant Ovarian Cancer Cells. J. Am. Chem. Soc. 2014, 136 (14), 5181-5184.

(21) McKinlay, A. C.; Xiao, B.; Wragg, D. S.; Wheatley, P. S.; Megson, I. L.; Morris, R. E. Exceptional Behavior over the Whole Adsorption-Storage-Delivery Cycle for NO in Porous Metal Organic Frameworks. J. Am. Chem. Soc. 2008, 130 (31), 10440-10444.

(22) Horcajada, P.; Chalati, T.; Serre, C.; Gillet, B.; Sebrie, C.; Baati, T.; Eubank, J. F.; Heurtaux, D.; Clayette, P.; Kreuz, C.; Chang, J.-S.; Hwang, Y. K.; Marsaud, V.; Bories, P.-N.; Cynober, L.; Gil, S.; Férey, G.; Couvreur, P.; Gref, R. Porous Metal-Organic-Framework Nanoscale Carriers as a Potential Platform for Drug Delivery and Imaging. Nat. Mater. 2010, 9, 172-178.

(23) Horcajada, P.; Gref, R.; Baati, T.; Allan, P. K.; Maurin, G.; Couvreur, P.; Ferey, G.; Morris, R. E.; Serre, C. Metal-Organic Frameworks in Biomedicine. Chem. Rev. 2012, 112, 1232-1268.

(24) Lucena, F. R. S.; de Araújo, L. C. C.; Rodrigues, M. do D.; da Silva, T. G.; Pereira, V. R. A.; Militão, G. C. G.; Fontes, D. A. F.; Rolim-Neto, P. J.; da Silva, F. F.; Nascimento, S. C. Induction of Cancer Cell Death by Apoptosis and Slow Release of 5-Fluoracil from Metal-Organic Frameworks Cu-BTC. Biomed. Pharmacother. 2013, 67, 707-713.

(25) Orellana-Tavra, C.; Baxter, E. F.; Tian, T.; Bennett, T. D.; Slater, N. K. H.; Cheetham, A. K.; Fairen-Jimenez, D. Amorphous 
Metal-Organic Frameworks for Drug Delivery. Chem. Commun. 2015, 51 (73), 13878-13992.

(26) Orellana-Tavra, C.; Marshall, R. J.; Baxter, E. F.; AbánadesLázaro, I.; Tao, A.; Cheetham, A. K.; Forgan, R. S.; Fairen-Jimenez, D. Drug Delivery and Controlled Release from Biocompatible MetalOrganic Frameworks Using Mechanical Amorphization. J. Mater. Chem. B 2016, 4 (47), 7697-7707.

(27) Abánades Lázaro, I.; Haddad, S.; Rodrigo-Muñoz, J.; Marshall, R.; Sastre, B.; del Pozo, V.; Fairen-Jimenez, D.; Forgan, R. S. SurfaceFunctionalisation of Zr-Fumarate MOF for Selective Cytotoxicity and Immune System Compatibility in Nanoscale Drug Delivery. ACS Appl. Mater. Interfaces 2018, 10, 31146-31157.

(28) Orellana-Tavra, C.; Haddad, S.; Marshall, R. J.; Abánades Lázaro, I.; Boix, G.; Imaz, I.; Maspoch, D.; Forgan, R. S.; FairenJimenez, D. Tuning the Endocytosis Mechanism of Zr-Based MetalOrganic Frameworks through Linker Functionalization. ACS Appl. Mater. Interfaces 2017, 9 (41), 35516-35525.

(29) Yang, H.; Qin, C.; Yu, C.; Lu, Y.; Zhang, H.; Xue, F.; Wu, D.; Zhou, Z.; Yang, S. RGD-Conjugated Nanoscale Coordination Polymers for Targeted T1- and T2-Weighted Magnetic Resonance Imaging of Tumors in Vivo. Adv. Funct. Mater. 2014, 24 (12), 17381747.

(30) Abánades Lázaro, I.; Haddad, S.; Rodrigo-Muñoz, J. M.; Orellana-Tavra, C.; Del Pozo, V.; Fairen-Jimenez, D.; Forgan, R. S. Mechanistic Investigation into the Selective Anticancer Cytotoxicity and Immune System Response of Surface-Functionalized, Dichloroacetate-Loaded, UiO-66 Nanoparticles. ACS Appl. Mater. Interfaces 2018, 10 (6), 5255-5268.

(31) Yang, B.; Shen, M.; Liu, J.; Ren, F. Post-Synthetic Modification Nanoscale Metal-Organic Frameworks for Targeted Drug Delivery in Cancer Cells. Pharm. Res. 2017, 34 (11), 2440-2450.

(32) Gao, X.; Zhai, M.; Guan, W.; Liu, J.; Liu, Z.; Damirin, A. Controllable Synthesis of a Smart Multifunctional Nanoscale MetalOrganic Framework for Magnetic Resonance/Optical Imaging and Targeted Drug Delivery. ACS Appl. Mater. Interfaces 2017, 9 (4), $3455-3462$.

(33) Zhou, H.; Fu, C.; Chen, X.; Tan, L.; Yu, J.; Wu, Q.; Su, L.; Huang, Z.; Cao, F.; Ren, X.; Ren, J.; Liang, P.; Meng, X. Mitochondria-Targeted Zirconium Metal-Organic Frameworks for Enhancing the Efficacy of Microwave Thermal Therapy against Tumors. Biomater. Sci. 2018, 6 (6), 1535-1545.

(34) Ni, K.; Lan, G.; Veroneau, S. S.; Duan, X.; Song, Y.; Lin, W. Nanoscale Metal-Organic Frameworks for Mitochondria-Targeted Radiotherapy-Radiodynamic Therapy. Nat. Commun. 2018, 9 (1), 4321.

(35) Bonnet, S.; Archer, S. L.; Allalunis-Turner, J.; Haromy, A.; Beaulieu, C.; Thompson, R.; Lee, C. T.; Lopaschuk, G. D.; Puttagunta, L.; Bonnet, S.; Harry, G.; Hashimoto, K.; Porter, C. J.; Andrade, M. A.; Thebaud, B.; Michelakis, E. D. A Mitochondria-K +Channel Axis Is Suppressed in Cancer and Its Normalization Promotes Apoptosis and Inhibits Cancer Growth. Cancer Cell 2007, 11 (1), 37-51.

(36) Madhok, B. M.; Yeluri, S.; Perry, S. L.; Hughes, T. a; Jayne, D. G. Dichloroacetate Induces Apoptosis and Cell-Cycle Arrest in Colorectal Cancer Cells. Br. J. Cancer 2010, 102 (12), 1746-1752.

(37) Tomas-Gamasa, M.; Martinez-Calvo, M.; Couceiro, J. R.; Mascarenas, J. L. Transition Metal Catalysis in the Mitochondria of Living Cells. Nat. Commun. 2016, 7, 12538.

(38) Boddapati, S. V.; D’Souza, G. G. M.; Erdogan, S.; Torchilin, V. P.; Weissig, V. Organelle-Targeted Nanocarriers: Specific Delivery of Liposomal Ceramide to Mitochondria Enhances Its Cytotoxicity in Vitro and in Vivo. Nano Lett. 2008, 8 (8), 2559-2563.

(39) Biswas, S.; Dodwadkar, N. S.; Deshpande, P. P.; Torchilin, V. P. Liposomes Loaded with Paclitaxel and Modified with Novel Triphenylphosphonium-PEG-PE Conjugate Possess Low Toxicity, Target Mitochondria and Demonstrate Enhanced Antitumor Effects in Vitro and in Vivo. J. Controlled Release 2012, 159 (3), 393-402.

(40) Bielski, E. R.; Zhong, Q.; Brown, M.; Da Rocha, S. R. P. Effect of the Conjugation Density of Triphenylphosphonium Cation on the
Mitochondrial Targeting of Poly(Amidoamine) Dendrimers. Mol. Pharmaceutics 2015, 12 (8), 3043-3053.

(41) Wang, H.; Mahle, J. J.; Tovar, T. M.; Peterson, G. W.; Hall, M. G.; DeCoste, J. B.; Buchanan, J. H.; Karwacki, C. J. Solid-Phase Detoxification of Chemical Warfare Agents Using Zirconium-Based Metal Organic Frameworks and the Moisture Effects: Analyze via Digestion. ACS Appl. Mater. Interfaces 2019, 11 (23), 21109-21116.

(42) Singh, M. P.; Dhumal, N. R.; Kim, H. J.; Kiefer, J.; Anderson, J. A. Influence of Water on the Chemistry and Structure of the MetalOrganic Framework $\mathrm{Cu}_{3}(\mathrm{Btc})_{2}$. J. Phys. Chem. C 2016, 120 (31), $17323-17333$.

(43) Morris, W.; Wang, S.; Cho, D.; Auyeung, E.; Li, P.; Farha, O. K.; Mirkin, C. A. Role of Modulators in Controlling the Colloidal Stability and Polydispersity of the UiO-66 Metal-Organic Framework. ACS Appl. Mater. Interfaces 2017, 9 (39), 33413-33418.

(44) Orellana-Tavra, C.; Mercado, S. A.; Fairen-Jimenez, D. FairenJimenez, D. Endocytosis Mechanism of Nano Metal-Organic Frameworks for Drug Delivery. Adv. Healthcare Mater. 2016, 5 (17), 2261-2270.

(45) Murphy, M. P. Targeting Lipophilic Cations to Mitochondria. Biochim. Biophys. Acta, Bioenerg. 2008, 1777 (7-8), 1028-1031.

(46) Gottwald, E. M.; Duss, M.; Bugarski, M.; Haenni, D.; Schuh, C. D.; Landau, E. M.; Hall, A. M. The Targeted Anti-Oxidant MitoQ Causes Mitochondrial Swelling and Depolarization in Kidney Tissue. Physiol. Rep. 2018, 6 (7), No. e13667.

(47) Zielonka, J.; Joseph, J.; Sikora, A.; Hardy, M.; Ouari, O.; Vasquez-Vivar, J.; Cheng, G.; Lopez, M.; Kalyanaraman, B. Mitochondria-Targeted Triphenylphosphonium-Based Compounds: Syntheses, Mechanisms of Action, and Therapeutic and Diagnostic Applications. Chem. Rev. 2017, 117 (15), 10043-10120.

(48) Shutt, T. E.; McBride, H. M. Staying Cool in Difficult Times: Mitochondrial Dynamics, Quality Control and the Stress Response. Biochim. Biophys. Acta, Mol. Cell Res. 2013, 1833 (2), 417-424.

(49) Frazier, A. E.; Kiu, C.; Stojanovski, D.; Hoogenraad, N. J.; Ryan, M. T. Mitochondrial Morphology and Distribution in Mammalian Cells. Biol. Chem. 2006, 387 (12), 1551-1558.

(50) Kamogashira, T.; Hayashi, K.; Fujimoto, C.; Iwasaki, S.; Yamasoba, T. Functionally and Morphologically Damaged Mitochondria Observed in Auditory Cells under Senescence-Inducing Stress. npj Aging Mech. Dis. 2017, 3 (1), 2.

(51) Mao, K.; Klionsky, D. J. Mitochondrial Fission Facilitates Mitophagy in Saccharomyces Cerevisiae. Autophagy 2013, 9 (11), 1900-1901.

(52) Dausend, J.; Musyanovych, A.; Dass, M.; Walther, P.; Schrezenmeier, H.; Landfester, K.; Mailander, V. Uptake Mechanism of Oppositely Charged Fluorescent Nanoparticles in HeLa Cells. Macromol. Biosci. 2008, 8, 1135-1143.

(53) Ferreira, C. G.; Span, S. W.; Peters, G. J.; Kruyt, F. A. E.; Giaccone, G. Chemotherapy Triggers Apoptosis in a Caspase-8Dependent and Mitochondria- Controlled Manner in the Non-Small Cell Lung Cancer Cell Line NCI-H460. Cancer Res. 2000, 60 (24), $7133-7141$.

(54) Wieder, T.; Essmann, F.; Prokop, A.; Schmelz, K.; SchulzeOsthoff, K.; Beyaert, R.; Dörken, B.; Daniel, P. T. Activation of Caspase-8 in Drug-Induced Apoptosis of B-Lymphoid Cells Is Independent of CD95/Fas Receptor-Ligand Interaction and Occurs Downstream of Caspase-3. Blood 2001, 97 (5), 1378-1387.

(55) Pirnia, F.; Schneider, E.; Betticher, D. C.; Borner, M. M. Mitomycin C Induces Apoptosis and Caspase-8 and -9 Processing through a Caspase-3 and Fas-Independent Pathway. Cell Death Differ. 2002, 9 (9), 905-914.

(56) Szklarczyk, D.; Franceschini, A.; Wyder, S.; Forslund, K.; Heller, D.; Huerta-Cepas, J.; Simonovic, M.; Roth, A.; Santos, A.; Tsafou, K. P.; Kuhn, M.; Bork, P.; Jensen, L. J.; von Mering, C. STRING V10: Protein-Protein Interaction Networks, Integrated over the Tree of Life. Nucleic Acids Res. 2015, 43, D447-D452.

(57) Young, L. J.; Ströhl, F.; Kaminski, C. F. A Guide to Structured Illumination TIRF Microscopy at High Speed with Multiple Colors. J. Visualized Exp. 2016, 111, 1-16. 
(58) Müller, M.; Mönkemöller, V.; Hennig, S.; Hübner, W.; Huser, T. Open-Source Image Reconstruction of Super-Resolution Structured Illumination Microscopy Data in ImageJ. Nat. Commun. 2016, $7,1-6$.

(59) Kamentsky, L.; Jones, T. R.; Fraser, A.; Bray, M. A.; Logan, D. J.; Madden, K. L.; Ljosa, V.; Rueden, C.; Eliceiri, K. W.; Carpenter, A. E. Improved Structure, Function and Compatibility for Cellprofiler: Modular High-Throughput Image Analysis Software. Bioinformatics 2011, 27 (8), 1179-1180. 